\title{
Hot compression behavior and microstructure of selectively laser-melted IN718 alloy
}

\author{
Ahmad Mostafa ${ }^{1}$ - Davood Shahriari ${ }^{2}$ Ignacio Picazo Rubio ${ }^{3} \cdot$ Vladimir Brailovski $^{2} \cdot$ Mohammad Jahazi $^{2}$. \\ Mamoun Medraj ${ }^{4}$
}

Received: 6 October 2017 / Accepted: 18 December 2017 / Published online: 22 January 2018

C) Springer-Verlag London Ltd., part of Springer Nature 2018

\section{Abstract}

The integration of additive manufacturing into traditional manufacturing processes presents the future of engineered components with similar or superior performance levels to wrought or cast materials. In this work, the hot-deformation behavior and the microstructural changes of heat-treated SLM-printed IN718 specimens are investigated. Samples having the same shape and size were 3D-printed, homogenized $\left(1100{ }^{\circ} \mathrm{C}, 1 \mathrm{~h}\right.$, and furnace-cooled), and hot-compressed, using a Gleeble 3800 physical simulator at 1000 and $1050{ }^{\circ} \mathrm{C}$ and 0.1 and $0.01 \mathrm{~s}^{-1}$ strain rates. A 3D diagram showing the effect of temperature and strain rate on the flow stress behavior of IN718 during hot deformation is plotted. The dynamic recrystallization (DRX) mechanism was dominant in all specimens tested at $0.1 \mathrm{~s}^{-1}$, while dynamic recovery (DRV) dominated in $0.01 \mathrm{~s}^{-1}$ tests. Changing the strain rate from 0.01 to $0.1 \mathrm{~s}^{-1}$ at $1000{ }^{\circ} \mathrm{C}$ increased the peak stress from 150 to $290 \mathrm{MPa}(93 \%)$, while with a temperature decrease from 1050 to $1000^{\circ} \mathrm{C}$ at $0.1 \mathrm{~s}^{-1}$, the peak stress increased by $45 \%$. Thus, the mechanical behavior was found to be more dependent on the strain rate than on the temperature. The DRX structure showed new grains developing at the boundaries of the original grains, whereas with the DRV structure, new grains grew within the original grains. A phenomenological model based on the ZenerHollomon parameter was proposed in order to predict the size of recrystallized grains during hot deformation of the SLM-printed IN718 superalloy. The thermal softening due to recrystallization was compensated by precipitation hardening, as was revealed by phase analysis.

Keywords Inconel $718 \cdot$ Additive manufacturing $\cdot$ Flow behavior $\cdot$ Gleeble ${ }^{\circledR}$ testing $\cdot$ DRX $\cdot$ DRV

Authors' accepted manuscript, article published in

The International Journal of Advanced Manufacturing Technology, vol. 96 issue 1-4, p. 371-385 (2018) https://doi.org/10.1007/s00170-017-1522-4

The final publication is available at link.springer.com 


\title{
Hot Compression Behavior and Microstructure of Selectively Laser-Melted IN718 Alloy
}

\author{
Ahmad Mostafa ${ }^{1}$, Davood Shahriari ${ }^{2}$, Ignacio Picazo Rubio ${ }^{3}$, Vladimir Brailovski ${ }^{2}$, \\ Mohammad Jahazi $^{2}$, and Mamoun Medraj ${ }^{* 4}$ \\ ${ }^{1}$ Department of Mechanical Engineering, Tafila Technical University, Tafila 66110, Jordan \\ ${ }^{2}$ Department of Mechanical Engineering, École de technologie supérieure, 1100 Notre-Dame Street West, Montreal, \\ Quebec H3C 1K3, Canada \\ ${ }^{3}$ Department of Mechanical and Materials Engineering, Masdar Institute of Science and Technology, Masdar City, Abu \\ Dhabi, P.O. Box 54224, UAE \\ ${ }^{4}$ Mechanical Engineering Department, Concordia University, 15151 rue Sainte Catherine Ouest, Montreal, QC, H3G \\ 2W1, Canada \\ Email of the corresponding author: mmedraj@encs.concordia.ca, Tel: +1-514-848-2424
}

\begin{abstract}
Integration of additive manufacturing into traditional manufacturing processes presents the future of engineered components with similar or superior performance levels to wrought or cast materials. In this work, the hot deformation behavior and the microstructural changes of heat-treated SLMprinted IN718 specimens are investigated. Samples having the same shape and size were 3D-printed, homogenized $\left(1100{ }^{\circ} \mathrm{C}, 1 \mathrm{~h}\right.$ and furnace-cooled) and hot-compressed, using a Gleeble ${ }^{\circledR} 3800$ physical simulator at 1000 and $1050{ }^{\circ} \mathrm{C}$ and 0.1 and $0.01 \mathrm{~s}^{-1}$ strain rates. A 3D diagram shows the effect of temperature and strain rate on the flow stress behavior of IN718 during hot deformation is plotted. The dynamic recrystallization (DRX) mechanism was dominant in all specimens tested at $0.1 \mathrm{~s}^{-1}$, while dynamic recovery (DRV) dominated in $0.01 \mathrm{~s}^{-1}$ tests. Changing the strain rate from 0.01 to 0.1 $\mathrm{s}^{-1}$ at $1000{ }^{\circ} \mathrm{C}$ increased the peak stress from 150 to $290 \mathrm{MPa}(93 \%)$, while with a temperature decrease from 1050 to $1000{ }^{\circ} \mathrm{C}$ at $0.1 \mathrm{~s}^{-1}$, the peak stress increased by $45 \%$. Thus, the mechanical behavior was found to be more dependent on the strain rate than on the temperature. The DRX structure showed new grains developing at the boundaries of the original grains, whereas with the DRV structure, new grains grew within the original grains. A phenomenological model based on the Zener-Hollomon parameter was proposed in order to predict the size of recrystallized grains during hot deformation of the SLM-printed IN718 superalloy. The thermal softening due to recrystallization was compensated by precipitation hardening, as was revealed by phase analysis.
\end{abstract}

Keywords: Inconel 718, additive manufacturing, flow behavior, Gleeble ${ }^{\circledR}$ testing, DRX, DRV 


\section{Introduction}

Thermomechanical processes are commonly used to alter the shapes of metals and alloys, while enhancing their properties through microstructural changes during deformation operations [1]. However, metals and alloys exhibit a very complex high temperature deformation behavior due to thermomechanical parameters, such as temperature, strain rate and strain intensity [2]. Additionally, dynamic recovery (DRV), dynamic recrystallization (DRX) and work hardening (WH) [3, 4] may affect their plastic deformation response through complex chemical and microstructural changes [5, $6]$.

IN718 alloy is extensively used in the production of critical parts for turbine engines and aerospace components, using hot deformation processes [7, 8], because it possesses exceptional structural properties at high temperatures. The low aluminum and titanium contents of this alloy improve its weldability [9], thus making it suitable for processing via selective laser melting (SLM). As a powder bed additive manufacturing technique, SLM [10,11] is ideally suited for the production of metallic parts with complex geometries, a feature that cannot be achieved by conventional manufacturing methods, such as casting or forging.

Today, 3D printing capabilities have been expanded exponentially in order to meet the evergrowing demand for complex and high-performance parts for aerospace applications. Alcoa Corporation [12] developed a new process called Ampliforge ${ }^{\mathrm{TM}}$, a new hybrid technique that combines additive manufacturing with traditional production processes [13]. With this technique, a part is designed and 3D-printed to its near net shape form, and then finished using a traditional manufacturing process, such as forging. The process significantly reduces material input and enhances the properties of 3D printed parts as compared to parts made merely by additive manufacturing.

Ideally, it would be less expensive to forge cast instead of wrought IN718 alloy to produce some engine components. However, altering the cast microstructure by forging to produce desired mechanical properties is not an easy feature. Hence, using 3D printed components in forging process is a promising approach that can reduce production cost, and at the same time, produce complex parts with desired microstructures. It is therefore crucial to understand the flow behavior of SLM-printed IN718 alloy during hot deformation processes, by which the microstructural and mechanical properties can be controlled to achieve different levels for various applications. Many studies have been carried out to characterize the high temperature flow behavior of wrought and cast IN718 alloys [6, 7, 14-18]. The high temperature deformation of IN718 alloys fabricated by additive manufacturing could not be found in the literature. The present work contributes to the research 
efforts [19-21] that aim at improving the ability of SLM to manufacture near net shape engineered and repeatable products to achieve similar or superior performances to the wrought or cast materials. In this paper, the high temperature flow behavior of heat-treated SLM-printed IN718 superalloy specimens and metallurgical changes resulting from hot deformation processes at different temperatures and strain rates are investigated.

\section{Experimental procedure}

In order to investigate the high temperature flow behavior of SLM-printed IN718 samples, hot compression tests were conducted on homogenized samples at two different temperatures and two strain rates. The chemical composition of the investigated IN718 superalloy powder, with an average size of $30 \mu \mathrm{m}$, is listed in Table 1, and is based on the data provided by the supplier [22] and that obtained in this work using energy dispersive X-ray spectroscopy (EDS) area analysis. Cylindrical shape test samples, measuring $12 \mathrm{~mm}$ in diameter and $20 \mathrm{~mm}$ in length, were printed in horizontal orientation, with their long axis being perpendicular to the building direction. The specimens were fabricated in a powder bed using an EOS M280 with $285 \mathrm{~W}$ Yb: YAG fiber laser system and Parameter Set IN718_Performance $1.0(40 \mu \mathrm{m}$ layer thickness, $100 \mu \mathrm{m}$ laser beam diameter, 0.11 hatch distance and $1000 \mathrm{~mm} / \mathrm{s}$ scanning speed). The homogenization treatment included heating the samples up to $1100{ }^{\circ} \mathrm{C}$ at a rate of $1^{\circ} \mathrm{C} / \mathrm{s}$, holding for $1 \mathrm{~h}$, and furnace-cooling. After this treatment, the as-printed specimens were machined down to $10 \mathrm{~mm}$ in diameter and $15 \mathrm{~mm}$ in length, using a traditional lathe machine.

Table 1: Chemical composition of as-received IN718 powder

\begin{tabular}{|c|c|c|}
\hline \multirow{2}{*}{ Element } & \multicolumn{2}{|c|}{ Weight \% } \\
\cline { 2 - 3 } & EOS-GmbH [22] & This work \\
\hline $\mathrm{Ni}$ & $50-55$ & 52.75 \\
\hline $\mathrm{Cr}$ & $17-21$ & 20.02 \\
\hline $\mathrm{Nb}$ & $4.75-5.5$ & 4.46 \\
\hline $\mathrm{Mo}$ & $2.8-3.3$ & 2.70 \\
\hline $\mathrm{Ti}$ & $0.65-1.15$ & 1.12 \\
\hline $\mathrm{Al}$ & $0.2-0.8$ & 0.45 \\
\hline $\mathrm{Co}$ & $\leq 1.0$ & - \\
\hline $\mathrm{Cu}$ & $\leq 0.3$ & - \\
\hline $\mathrm{C}$ & $\leq 0.08$ & - \\
\hline $\mathrm{Si}, \mathrm{Mn}$ & Each $\leq 0.35$ & - \\
\hline $\mathrm{P}, \mathrm{S}$ & Each $\leq 0.015$ & - \\
\hline $\mathrm{B}$ & $\leq 0.006$ & - \\
\hline $\mathrm{Fe}$ & Balance & Balance \\
\hline
\end{tabular}

The high temperature compression test was performed using a Gleeble ${ }^{\circledR} 3800$ thermomechanical simulator. The test samples were conductively heated to 1000 and $1050{ }^{\circ} \mathrm{C}$ at a heating rate of $1{ }^{\circ} \mathrm{C} / \mathrm{s}$, 
held for $120 \mathrm{~s}$, compressed at strain rates of 0.1 and $0.01 \mathrm{~s}^{-1}$, and then cooled at $150{ }^{\circ} \mathrm{C} / \mathrm{s}$. The test stopped when an $80 \%$ true strain was reached. The homogenization treatment and Gleeble ${ }^{\circledR}$ test procedure are shown graphically in Figure 1(a). The temperature distribution along the samples was acquired using three thermocouples attached to the mid-height and close to the top and bottom of the cylinder.

In order to minimize the friction between the specimens and the anvils, a $0.1 \mathrm{~mm}$ thick tantalum foil was used for lubrication. High load cell module and lengthwise transducer system were used to precisely measure the force exerted on the specimen and the length change of the sample during hot compression experiments. Therefore, true stress-strain curves were drawn from the measured loaddisplacement (compliance) data. The experimental setup of the Gleeble ${ }^{\circledR}$ test is shown in Figure 1(b). The flow stress was measured under different deformation temperatures and strain rates, as summarized in Table 2. The letters A, B, C and D are used in this paper to refer to the corresponding testing conditions.
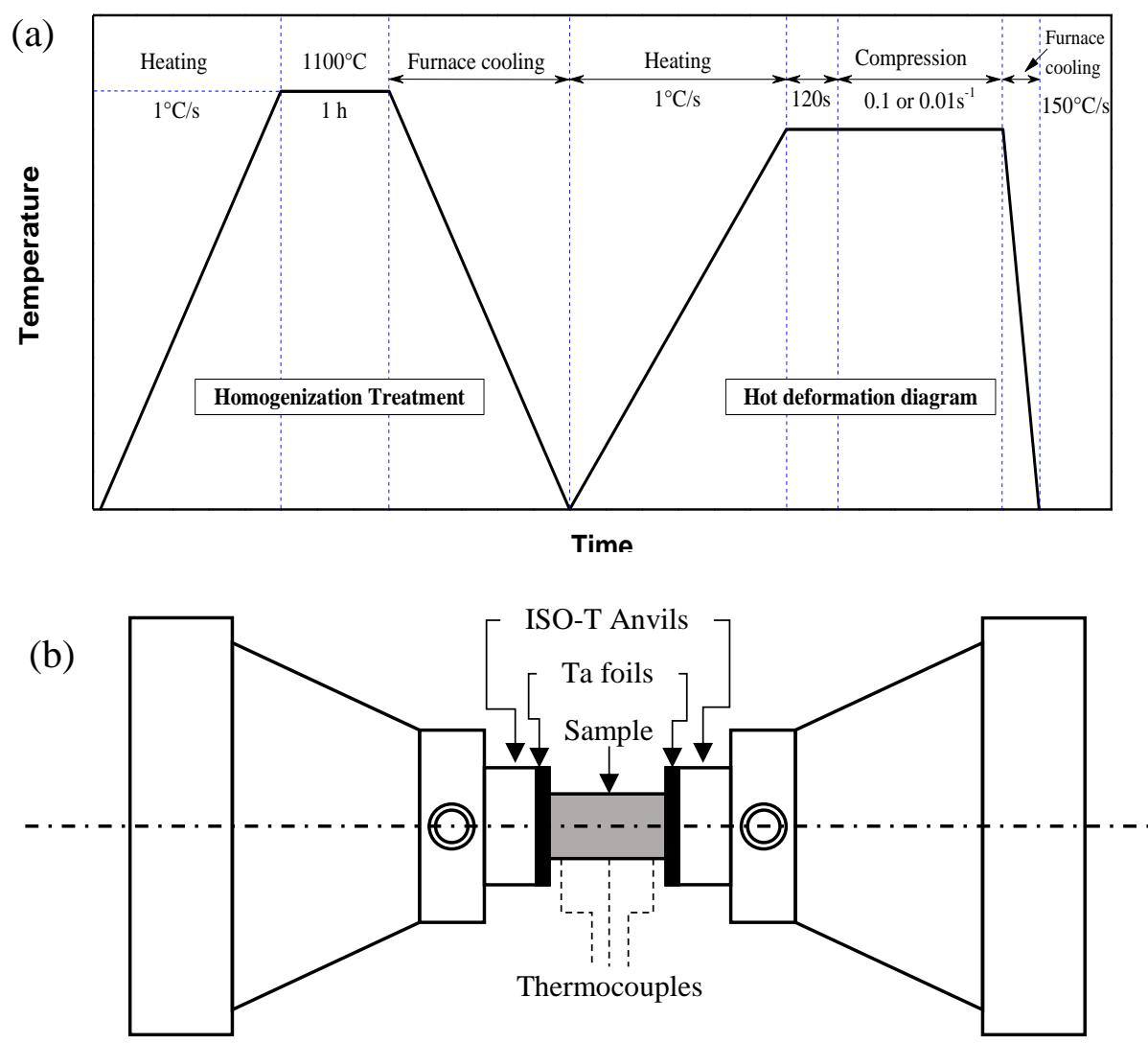

Figure 1: (a) Thermal cycles graph, including the homogenization treatment and hot deformation procedures and (b) Gleeble ${ }^{\circledR}$ test experimental setup.

Table 2: High temperature compression test parameters

\begin{tabular}{|c|c|c|}
\hline Test & Temperature $\left({ }^{\circ} \mathbf{C}\right)$ & Strain rate $\left(\mathbf{s e c}^{-1}\right)$ \\
\hline A & 1000 & 0.10 \\
\hline B & 1050 & 0.10 \\
\hline
\end{tabular}




\begin{tabular}{|l|l|l|}
\hline $\mathbf{C}$ & 1000 & 0.01 \\
\hline $\mathbf{D}$ & 1050 & 0.01 \\
\hline
\end{tabular}

The tested specimens were cut along the compression axis using a slow cutting blade in a mineral oil bath to eliminate heat generation. Sectioned samples were mounted in a hot-setting epoxy resin for metallographic sample preparation. The surfaces of the mounted samples were gradually ground down to 1200 grit using SiC papers. Water was used as a lubricant and a coolant during grinding. The ground samples were polished down to $0.25 \mu \mathrm{m}$ using alcohol-based diamond suspension. An FEI Quanta 250 field emission gun scanning electron microscope (FEG-SEM), equipped with an EDS and an HKL electron backscattered diffraction (EBSD) detector, was used for microstructural studies. EDS analysis was used for further microstructural investigation and compositional analysis. EBSD experiments were used to describe the crystal orientations, grain shapes and crystallographic textures of starting as well as tested materials.

\section{Results and discussion}

\subsection{Influence of deformation parameters on the flow stress}

The plastic flow behavior curves were obtained by compression testing at 1000 and $1050{ }^{\circ} \mathrm{C}$ and at strain rates of 0.1 and $0.01 \mathrm{~s}^{-1}$ using the Gleeble ${ }^{\circledR}$ testing equipment. Typical experimental curves of hot compression true stress-true strain data are presented in Figure 2. These curves are in agreement with the corresponding true stress-true strain curves obtained from high temperature compression testing of conventionally-processed IN718 alloy [17, 23]. Figure 2 (a) and (b) show the effect of temperature on the IN718 plastic flow behavior at 0.1 and $0.01 \mathrm{~s}^{-1}$ strain rates, respectively. The designated test letters (A, B, C and D) correspond to those in Table 2.

The flow stress curves obtained at a given strain rate of $0.1 \mathrm{~s}^{-1}$ (Figure 2a) and $0.01 \mathrm{~s}^{-1}$ (Figure 2b) exhibit similar behavior, regardless of the testing temperature. At a strain rate of $0.1 \mathrm{~s}^{-1}$ (Figure 2a), both tests A and B show two-peak flow stress curves, with a sharp stress peak at low strains followed by a broader peak reaching a maximum, with a subsequent decrease in flow stress at high strain zones. In tests C and D (Figure 2 (b), the strain rate was reduced to $0.01 \mathrm{~s}^{-1}$, and the flow stress increased up to its maximum level at low strains, then monotonously decreased and stabilized. To understand these different responses, the metallurgical aspects that control the flow stress behavior during the high temperature deformation are investigated. 

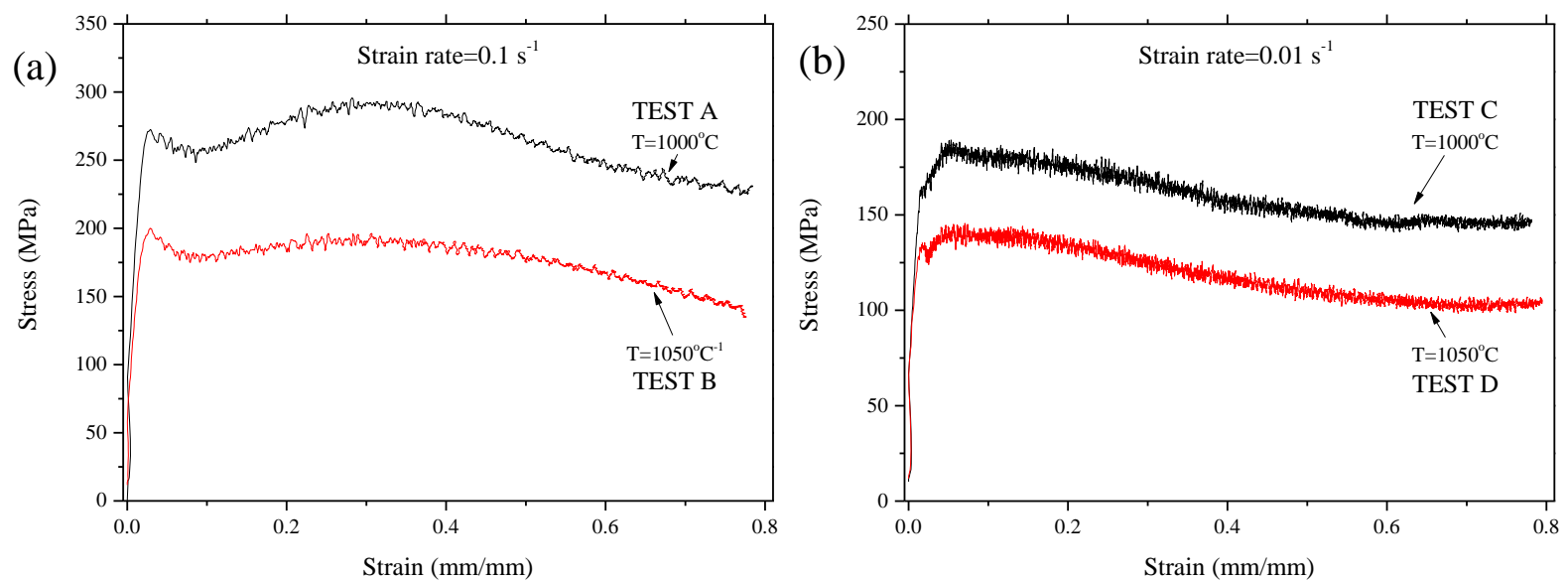

Figure 2: True stress-true strain curves for IN718 alloys at (a) $0.1 \mathrm{~s}^{-1}$, and (b) $0.01 \mathrm{~s}^{-1} \mathrm{strain}$ rates.

During hot deformation, the material may undergo work hardening, dynamic recovery, dynamic recrystallization [3], and/or precipitation strengthening [15]. In the case of IN718 alloy, due to its relatively low stacking fault energy[24], the softening due to dynamic recovery is small and the high dislocations density promotes the onset of $\operatorname{DRX}[2,25]$. The small drop "after yield peak" observed in the stress-strain curves at the higher strain rate in Figure 2 (a) has been also observed by other workers $[15,26-28]$ and is associated with the occurrence of very localized DRX followed by hardening, short range ordering of solutes $(\mathrm{Nb}, \mathrm{Ti}, \mathrm{Al})$, or interaction between strain induced precipitation ( $\gamma^{\prime \prime}$, carbides) and DRX. However, the determination of the exact origin of the yield drop requires a specific study and is out of the scope of the present work. Therefore, from Figure 2 (a), it can be concluded that DRX is the dominating mechanism during the hot deformation process at $0.1 \mathrm{~s}^{-1}$ strain rate.

The stress-strain curves at the lower strain rate, Figure 2(b) show that the flow stress decreases with the strain at a constant rate. This indicates that the slow deformation rate allows the material to reduce its deformation energy by rearranging or annihilating of dislocations. Thus, the flow stress remains in a steady trend or drops slightly due to the balance between the work hardening and the DRV [3]. While the occurrence of DRX cannot be ignored, it is probable that its contribution will be minor due to the slow strain rate and, therefore, the flow stress behavior at a $0.01 \mathrm{~s}^{-1}$ strain rate shown in Figure 2 (b) is mainly governed by the DRV mechanism.

It is worth noting that the peak stresses increased with decreasing the testing temperature, at a fixed strain rate, whereas at a fixed testing temperature, the peak stresses increased with an increase in the strain rate. Similar behaviors have been obtained by other researchers for IN718 and other Ni 
base superalloys $[26,29]$. The lowest strength during hot deformation processes can be achieved by decreasing the strain rate and increasing the processing temperature. This conclusion stems from the fact that under lower temperatures and/or high strain rate conditions, the time and energy are not sufficient for the nucleation and growth of new dynamically recrystallized grains. As a result, the process will be dominated by work hardening rather than softening by either the DRV or DRX mechanisms [3]. On the contrary, increasing the temperature or decreasing the strain rate decreases the flow stress level, since the time and energy are adequate to generate dynamically recovered and recrystallized grains.

\subsection{Effects of temperature and strain rate on the flow stress behavior}

With reference to the true stress-strain curves in Figure 2, the effects of temperature and strain rate on the flow stress behavior of IN718 alloy during hot deformation testing is demonstrated in Figure 3.

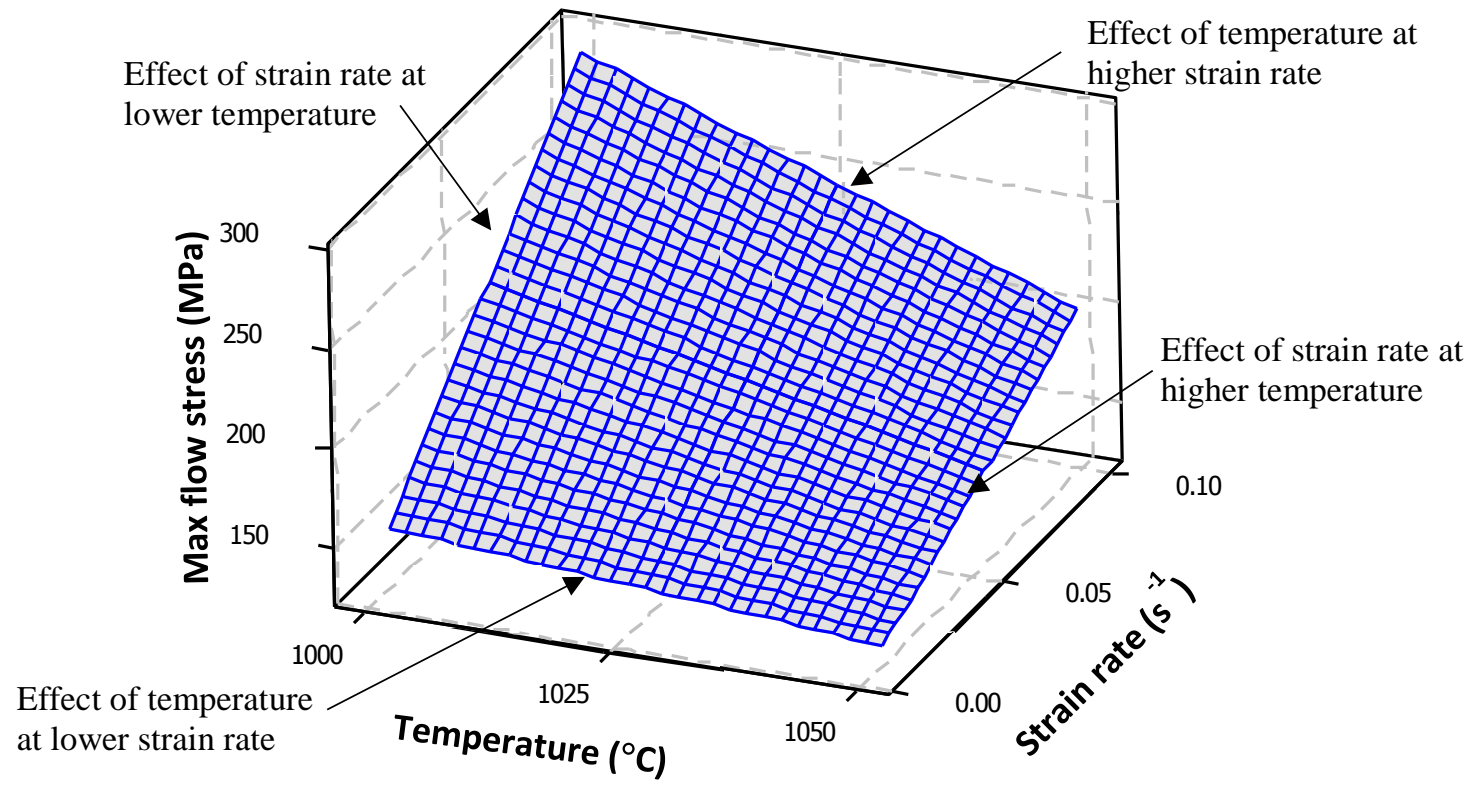

Figure 3: Effects of temperature and strain rate on the maximum flow behavior of IN718 during hot deformation

Although the interaction of both parameters greatly influences the maximum flow stress value, the effect of the strain rate is greater than that of the temperature, within the limits of the present experimental study. For example, at $0.01 \mathrm{~s}^{-1}$ and $1000{ }^{\circ} \mathrm{C}$, the maximum flow stress is $150 \mathrm{MPa}$, whereas at the same temperature, but at a higher strain rate $\left(0.1 \mathrm{~s}^{-1}\right)$, the maximum flow stress can go up to $290 \mathrm{MPa}$. From this example, a tenfold increase in strain rate leads to a $93 \%$ increase in the 
flow stress. On the other hand, a temperature decrease from 1050 to $1000{ }^{\circ} \mathrm{C}$ at $0.1 \mathrm{~s}^{-1}$ only increases the flow stress by $45 \%$ (from 200 to $290 \mathrm{MPa}$ ). It is therefore concluded that the mechanical properties of IN718 are highly strain rate-dependent.

The variations of the flow stress behavior under different temperatures and strain rates are normally associated with metallurgical and microstructural changes. The following section represents an attempt to understand the microstructure evolution and correlate the phase transformation phenomena with the flow stress response during hot deformation tests.

\subsection{Radial and longitudinal thermal gradients}

Figure 4 shows the geometrical changes that occurred for the test samples after Gleeble ${ }^{\circledR}$ testing. A cylindrical shape test sample, with initial dimensions of $\varnothing=10 \mathrm{~mm}$ and $L=15 \mathrm{~mm}$, shown in Figure 4 (a), was compressed until an $80 \%$ true strain was reached. Figure 4 (b) shows the shape and dimensions of the sample after compression testing. After the test, the sample exhibits asymmetric geometries in respect to the transverse center plane. The diameters of the top and bottom bases are 13 and $15.2 \mathrm{~mm}$, respectively, with a maximum bulging diameter of $16 \mathrm{~mm}$ at the center. This geometrical asymmetry could be attributed to the temperature gradient present in the sample during the experiments.

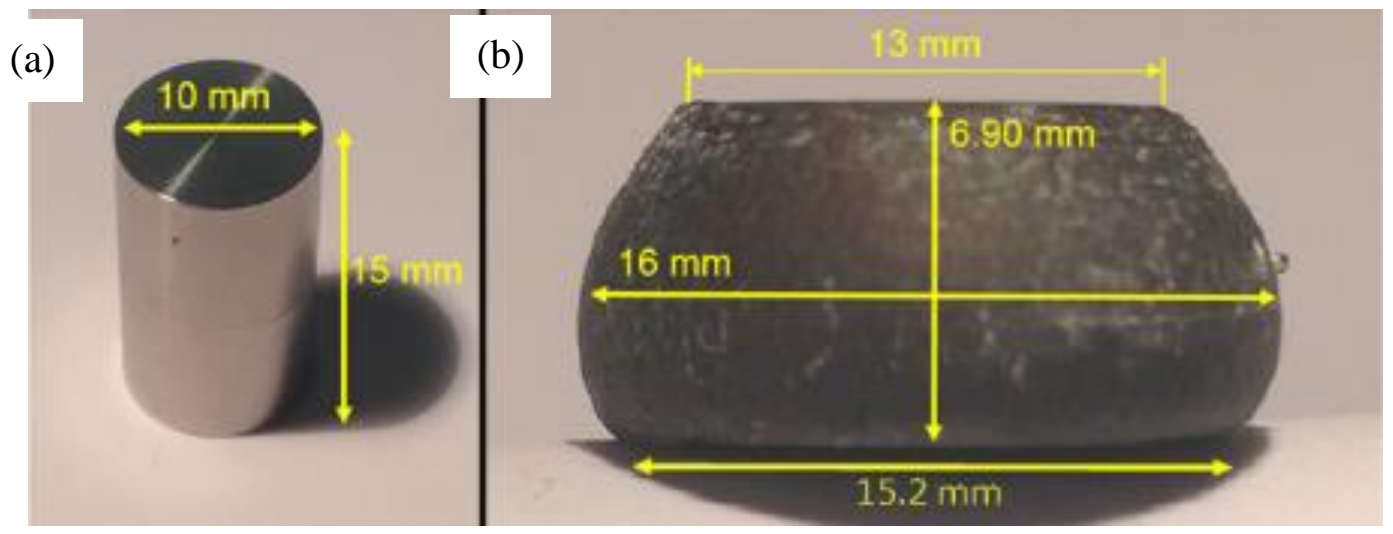

\section{Figure 4: (a) Cylindrical test sample before Gleeble ${ }^{\circledR}$ test; (b) Deformed sample after Gleeble ${ }^{\circledR}$ test.}

The presence of axial and radial thermal gradients during Gleeble ${ }^{\circledR}$ thermomechanical testing has been reported in the literature [19, 30-33]. However, the severity and the extent of the gradient depends on the detailed experimental setup (e.g., use of copper or stainless grips) and the thermophysical properties of the investigated material. For example, Zhang et al. [33] measured a longitudinal temperature profiles along the surface of a high strength steel sample and reported about $40{ }^{\circ} \mathrm{C}$ within a $5 \mathrm{~mm}$ distance from the center towards the two ends. They also reported temperature 
gradients in the radial direction. Using ISO-T anvils with stainless grips, the present authors were able to reduce the thermal gradient for a similar steel to less than $5^{\circ} \mathrm{C}[30]$.

In this study, the central point of the specimen hosted the control thermocouple and the other two points, each located at about $3.75 \mathrm{~mm}$ from the sample edges, hosted a reference thermocouple. The longitudinal temperature gradient measured under these conditions was about $20{ }^{\circ} \mathrm{C}$ between the control and the reference thermocouples. Figure 5 demonstrates the time vs. temperature plots obtained from three thermocouples. Similar differences have also been observed in a nickel-based superalloy by Bennette et al. [19].

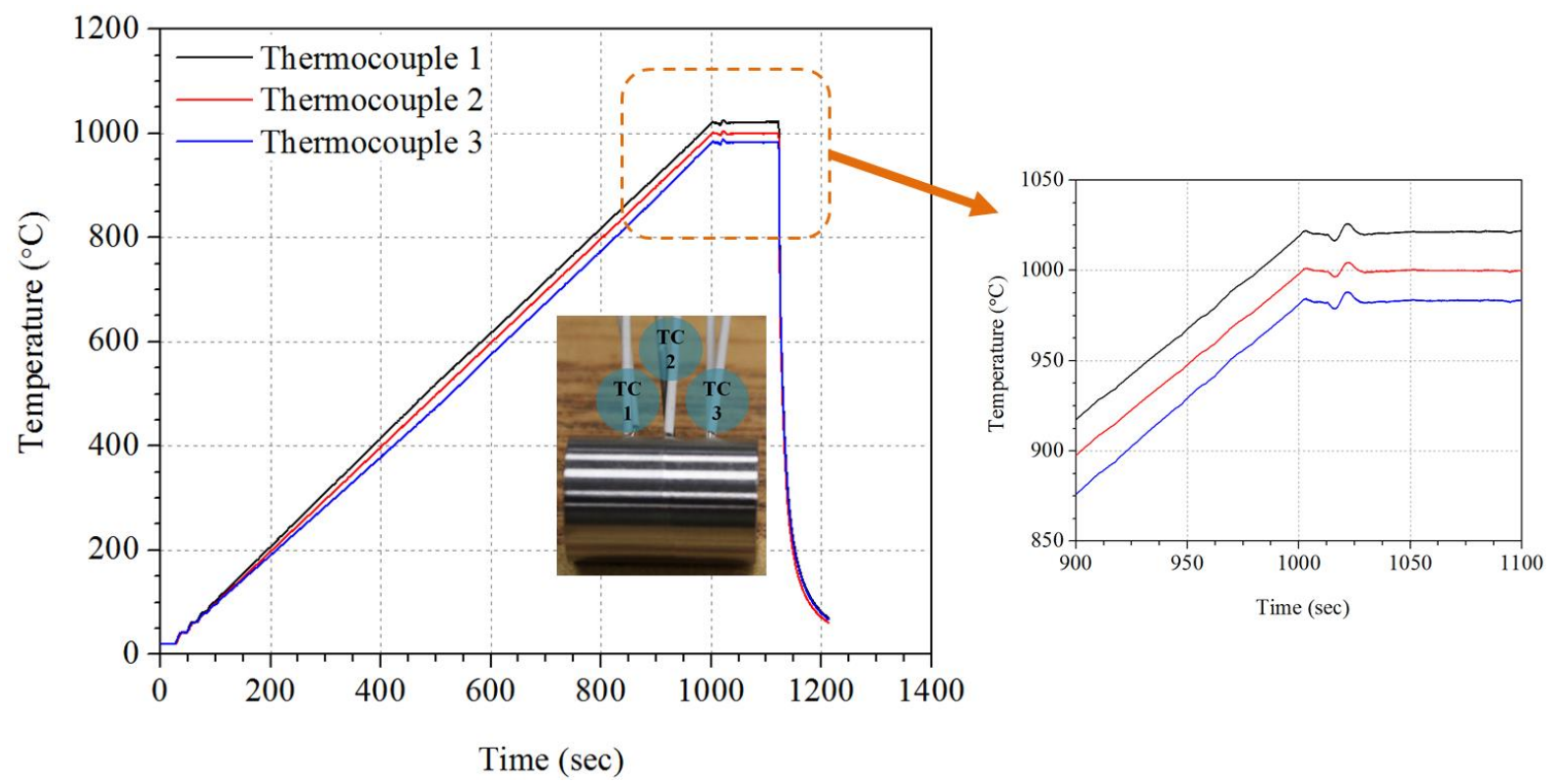

Figure 5: Measured axial temperature variations at the surface of SLM-printed IN718 by three thermocouples during Gleeble ${ }^{\circledR}$ test.

Finally, it should be noted that temperature gradients are directly proportional to the emissivity and the electrical resistivity but inversely proportional to the thermal conductivity of the tested material. A very accurate analysis would require determining the thermophysical properties of the SLM-printed material. Such data are not available in the literature, and presently, the thermophysical properties of conventionally produced IN718 are generally used by researchers in the design, analysis, and modeling of additively-manufactured parts. The same approach was used in this work, since the determination of such constants was out of its scope.

\subsection{Texture and grain size analysis}

Numerous microstructural changes and phase evolutions are expected to occur inside the sample due to radial and longitudinal temperature gradients, besides the effect of the Gleeble ${ }^{\circledR}$ test parameters, e.g., testing temperature and strain rate. In order to monitor the microstructural changes 
after the test, the characteristics of the starting alloy must be identified. Prior to testing, samples were printed horizontally with respect to the building direction, and their microstructure was refined using a homogenization treatment $\left(1100{ }^{\circ} \mathrm{C}\right.$, held for $1 \mathrm{~h}$, and then cooled in furnace). EBSD analysis revealed that after the homogenization treatment, the texture contains equiaxed-columnar mixed grains, as shown in Figure 6 (a), which is dissimilar to the as-printed texture which is composed of columnar grains only [34]. Figure 6 (b) represents the grain size distribution chart of the starting homogenized alloy. The average grain size in both the vertical and horizontal sections was consistent, at about $50 \mu \mathrm{m}$. The adopted thermal treatment in this work led to homogenous grain growth in all directions, without any preference given to the building direction.

Tests A to D showed different microstructures and grain sizes along the vertical cross-section from those of the starting specimens. The samples tested at the same strain rate and grouped in either Figure 2 (a) or (b), demonstrate almost similar microstructural features. For instance, Tests A and B were performed at $0.1 \mathrm{~s}^{-1}$ and were found to have similar microstructural features. Equally, Tests $\mathrm{C}$ and $\mathrm{D}$ were performed at $0.01 \mathrm{~s}^{-1}$ and their microstructures were also similar. Because of this similarity, one sample from each pair, namely, Tests A and D, was selected for further discussion and comparison. The selection criterion was based on the highest and lowest flow stress values obtained during Gleeble ${ }^{\circledR}$ tests. In Test A, the highest flow stress, $290 \mathrm{MPa}$, was obtained at $1000{ }^{\circ} \mathrm{C}_{\text {and }} 0.1 \mathrm{~s}^{-}$ ${ }^{1}$, while the lowest flow stress, $130 \mathrm{MPa}$, was obtained in Test $\mathrm{D}$ at $1050{ }^{\circ} \mathrm{C}$ and $0.01 \mathrm{~s}^{-1}$. Figure 7 and 8 show the grain directions and crystallographic textures of the above samples. 
(a)
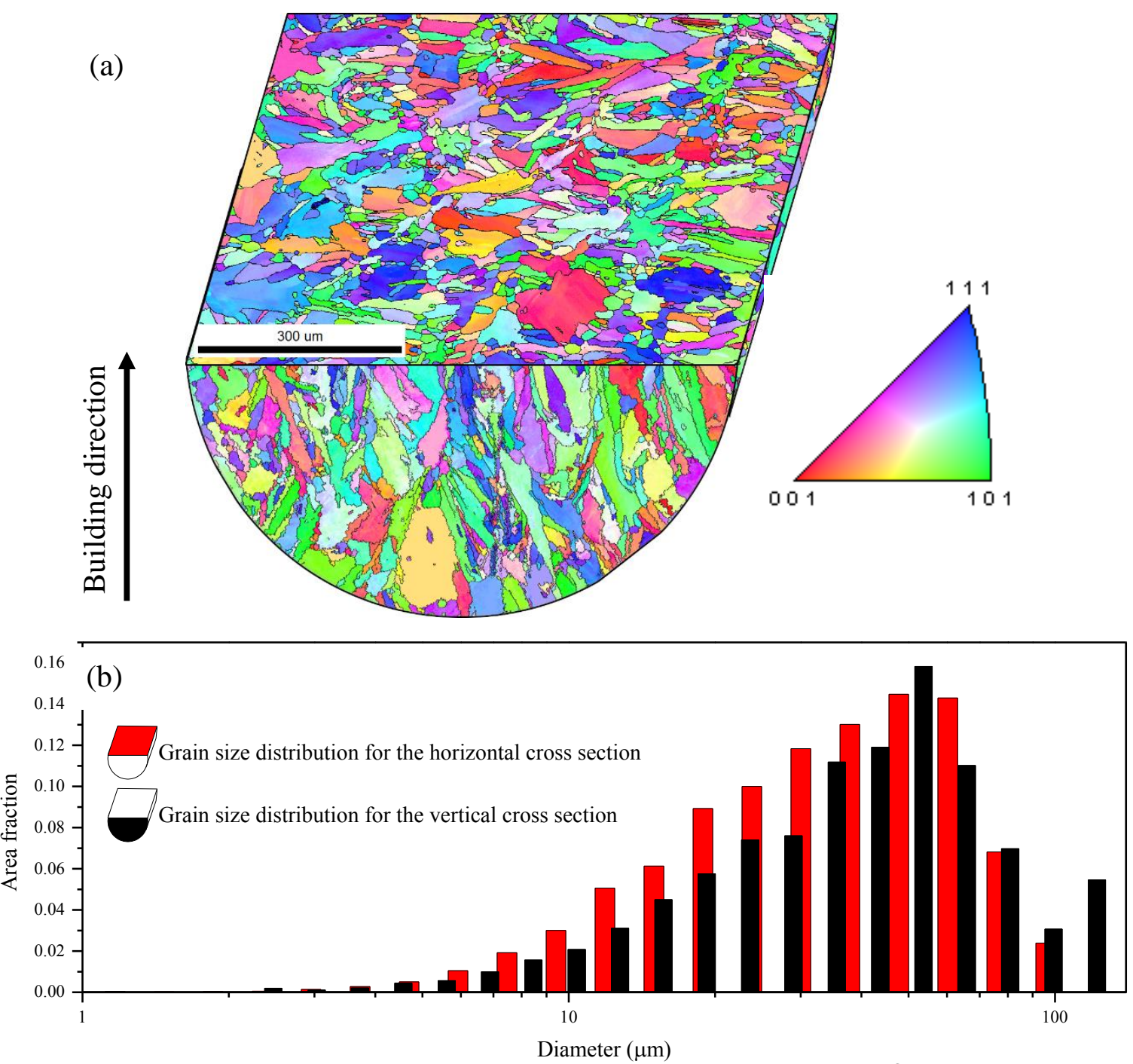

Figure 6: (a) EBSD 3D map for homogenized sample prior to Gleeble ${ }^{\circledR}$ test associated with inverse pole index, and (b) Grain size distribution chart for both vertical and horizontal sections.

EBSD scans were performed at three different locations along the longitudinal axis (at the center near the short and long edges), as illustrated by the inset at the lower corner of the right column images of Figure 7 and 8. The crystallographic orientations are described using an inverse pole index in the insets of the left column images. It is worth mentioning that a small fraction of non-indexed points was visible in the EBSD scans due to the presence of fine precipitates and scratches. To eliminate these features, image cleanup was performed using an orientation imaging microscopy (OIM) software package. The cleanup was carried out using the methods of a neighbor confidence index $(\mathrm{CI})$ correlation of $\geq 0.1$ and a grain dilation with a grain tolerance angle of $5^{\circ}$. After the cleanup process, the orientation of the non-indexed points was changed to match any of the neighboring indexed grains or to randomly selected neighboring points not belonging to any grain. 
One to three iterations of both the neighbor CI correlation and grain dilation methods were applied to make each point a member of a grain.
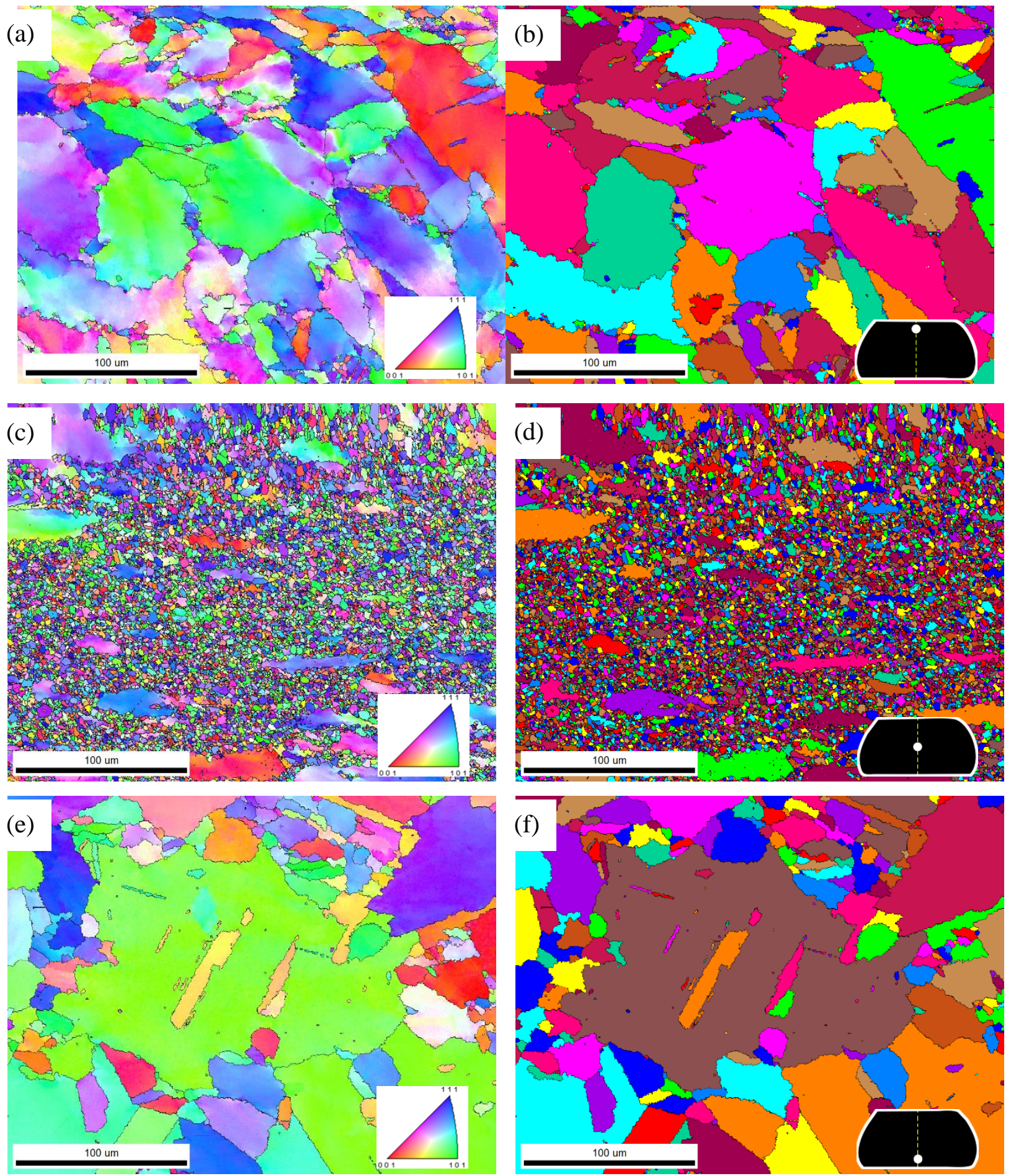

Figure 7: EBSD maps of Test A sample $\left(1000{ }^{\circ} \mathrm{C}, 0.1 \mathrm{~s}^{-1}\right)$; left column shows inverse pole figures and right column shows unique grain maps $(a, b)$ near the short edge; $(c, d)$ at the center; and (e, f) near the long edge. 

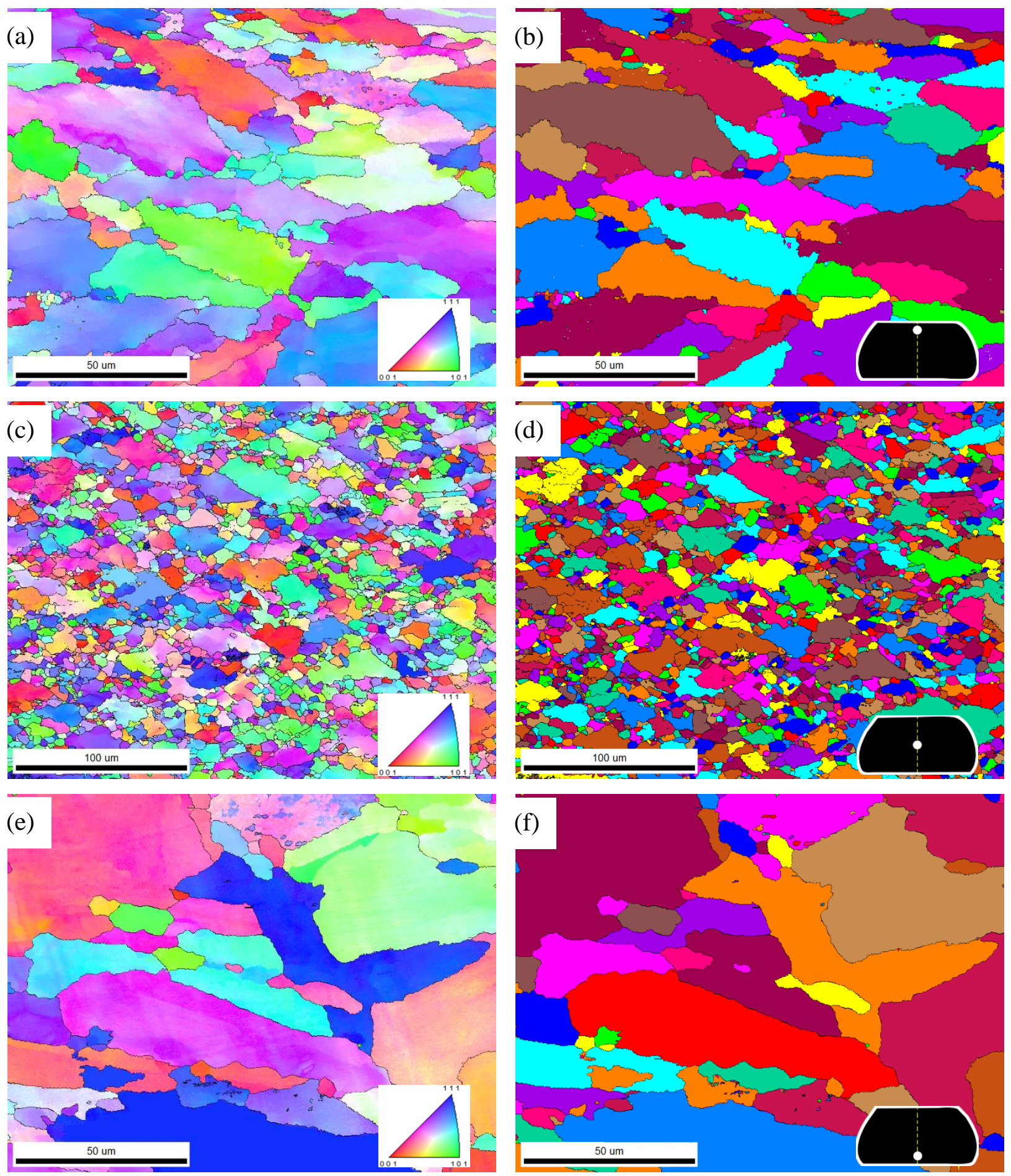

Figure 8: EBSD maps of Test D sample $\left(1050{ }^{\circ} \mathrm{C}, 0.01 \mathrm{~s}^{-1}\right)$; left column shows inverse pole figures and right column shows unique grain maps $(a, b)$ near the short edge; $(c, d)$ at the center; and (e, f) near the long edge.

After the Gleeble ${ }^{\circledR}$ tests, the homogenized microstructure transformed into an assembly of unevenly distributed equiaxed grains of different sizes and orientations, with the microstructure near 
the edges being different from that observed at the center. The average grain size distributions for both Tests A and D are plotted in Figure 9 (a) and (b), respectively.

(a)

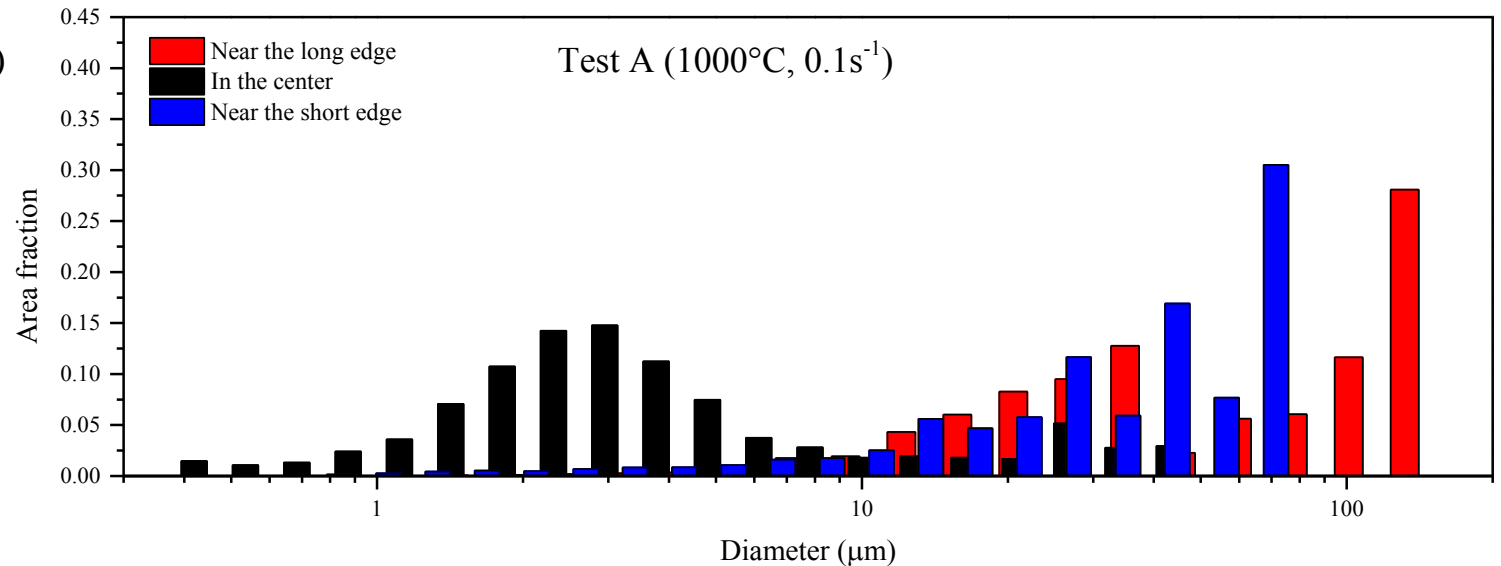

(b)

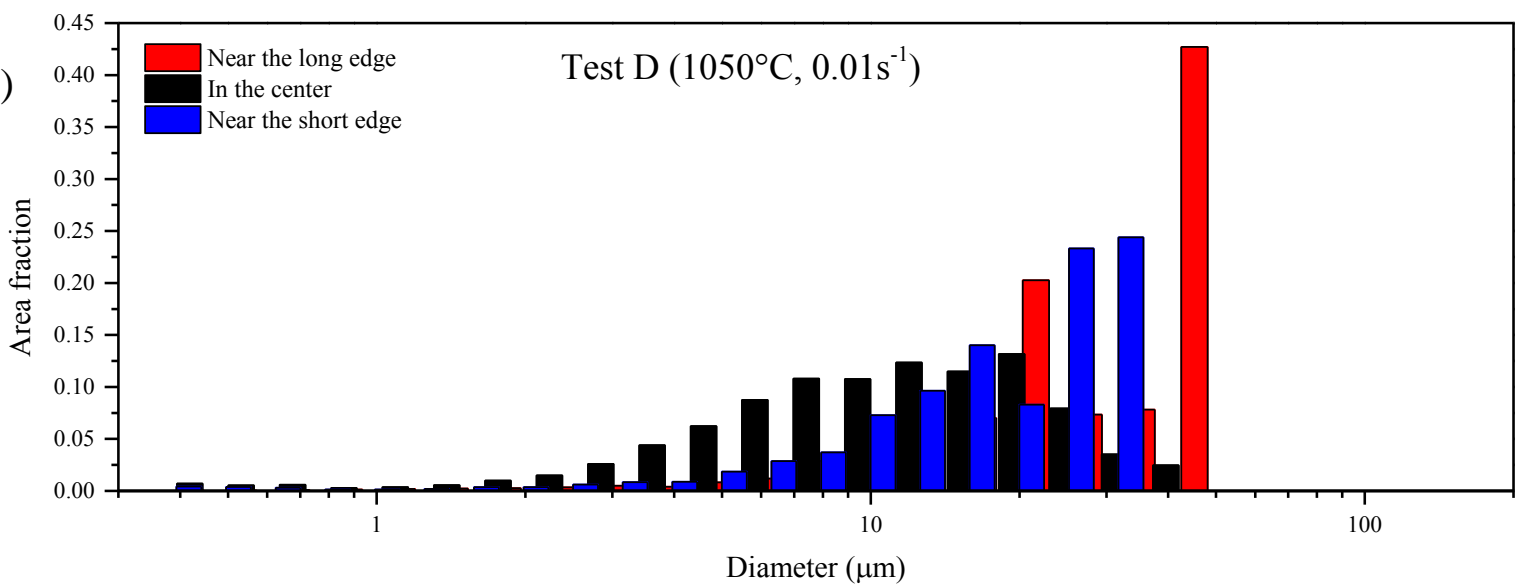

Figure 9: Grain size distribution near the long edge, at the center, and near the short edge of (a) Test A, and (b) Test D.

The average grain sizes near the short and long edges of Test A, Figure $7(a, b)$ and $(e, f)$, were $\sim 80$ and $\sim 105 \mu \mathrm{m}$, respectively. The center shows the development of new recrystallized grains with different orientations and an average size of about $3 \mu \mathrm{m}$. The new recrystallized grains were formed along the initial grain boundaries, and none inside the original grains. This is illustrated in Figure 7 (c) and (d), where the microstructure shows work-hardened grains surrounded by dynamically recrystallized grains. A similar DRX microstructure was observed by Wang et al. [16] for a sample tested at $1100{ }^{\circ} \mathrm{C}$ and $0.1 \mathrm{~s}^{-1}$.

In contrast, the average grain sizes near the short and long edges of Test D, Figure $8(\mathrm{a}, \mathrm{b})$ and $(\mathrm{e}, \mathrm{f})$, were about 35 and $50 \mu \mathrm{m}$, respectively. The structure at the center of the Test D sample contains grains with an average size of $10.2 \mu \mathrm{m}$. Unlike the DRX structure, the new developed grains in Figure 8 (c) and (d) grew within the original grains. Moreover, the original grains did not maintain the work hardening structure. The absence of a work hardening structure is due to 
slow loading with low strain rates at higher temperatures, which led to thermal softening by the DRX and DRV mechanisms. Thus, both the maximum flow stress and the onset of a steady state flow were shifted to lower strain levels. This conclusion is in agreement with the flow stress behavior exhibited in Figure 2 (b) for Tests $\mathrm{C}$ and $\mathrm{D}$, with a $0.01 \mathrm{~s}^{-1}$ strain rate. Because of the aforementioned results, the Test $\mathrm{D}$ conditions are recommended for industry so that the deformation energy is minimum and the structure is more homogeneous

In general, the deformation temperature and the strain rate are two critical factors during hot deformation. The flow stress can be characterized by the Zener-Hollomon parameter $(Z)$, which is described as [35]:

$$
\mathrm{Z}=\dot{\varepsilon} \exp \left(\frac{\mathrm{Q}}{\mathrm{RT}}\right)
$$

where $\mathrm{R}$ is the gas constant $\left(8.314 \mathrm{~J} \cdot \mathrm{mol}^{-1} \cdot \mathrm{K}^{-1}\right), \mathrm{Q}$, the apparent hot working activation energy $\left(\mathrm{J} \cdot \mathrm{mol}^{-}\right.$ $\left.{ }^{1}\right), \dot{\varepsilon}$, the strain rate $\left(\mathrm{s}^{-1}\right)$ and $\mathrm{T}$, the deformation temperature $(\mathrm{K})$. Hence, $\mathrm{Z}$ can be used to represent the combined effects of strain rate and temperature on the recrystallized grain size. The Z parameter for the dynamic recrystallization is defined by [24]:

$$
\mathrm{D}_{\mathrm{DRX}}=\mathrm{AZ}^{-\beta}
$$

where $A$ and $\beta$ are the material constants.

Based on the above analysis, and using the stress-strain data presented in Figure 2, the apparent activation energy and the values of $A$ and $\beta$ for the SLM-printed IN718 were estimated as 474 $\mathrm{KJ}_{\mathrm{mol}}{ }^{-1}, 3 \times 10^{5}$ and 0.27 , respectively. It is desirable to determine in which critical condition (process parameter), DRX would be the dominant softening mechanism. Thus, a polynomial expression is suggested to find this region. The recrystallized grain size evolution can be modeled as a function of the Zener-Hollomon parameter using the following second-order polynomial function:

$$
\mathrm{D}_{\mathrm{DRX}}=395.59972-17.75856(\mathrm{LnZ})+0.20056(\mathrm{LnZ})^{2}
$$

The established model can be used to predict the recrystallized grain size during the hot deformation process of the SLM-printed IN718. Figure 10 shows a comparison between the experimental and the predicted recrystallized grain size for the SLM-printed and wrought IN718 superalloy [36]. It can be seen that finer recrystallized grains are formed at higher Z values in both asprinted IN718 and wrought materials, especially after hot deformation at $1000{ }^{\circ} \mathrm{C}$ and at a $0.01 \mathrm{~s}^{-1}$ strain rate. This trend is also in good agreement with that reported by Zhou and Baker [4] for wrought IN718 superalloy. This may be attributed to the fact that the recrystallized grains can easily coarsen at a $0.01 \mathrm{~s}^{-1}$ strain rate in the $1000-1050{ }^{\circ} \mathrm{C}$ forming temperature range. It is 
important to note that the DRX mechanism appears to be the dominant softening mechanism for the deformation regimes corresponding to " $\mathrm{LnZ} \geq 40.5$ ".

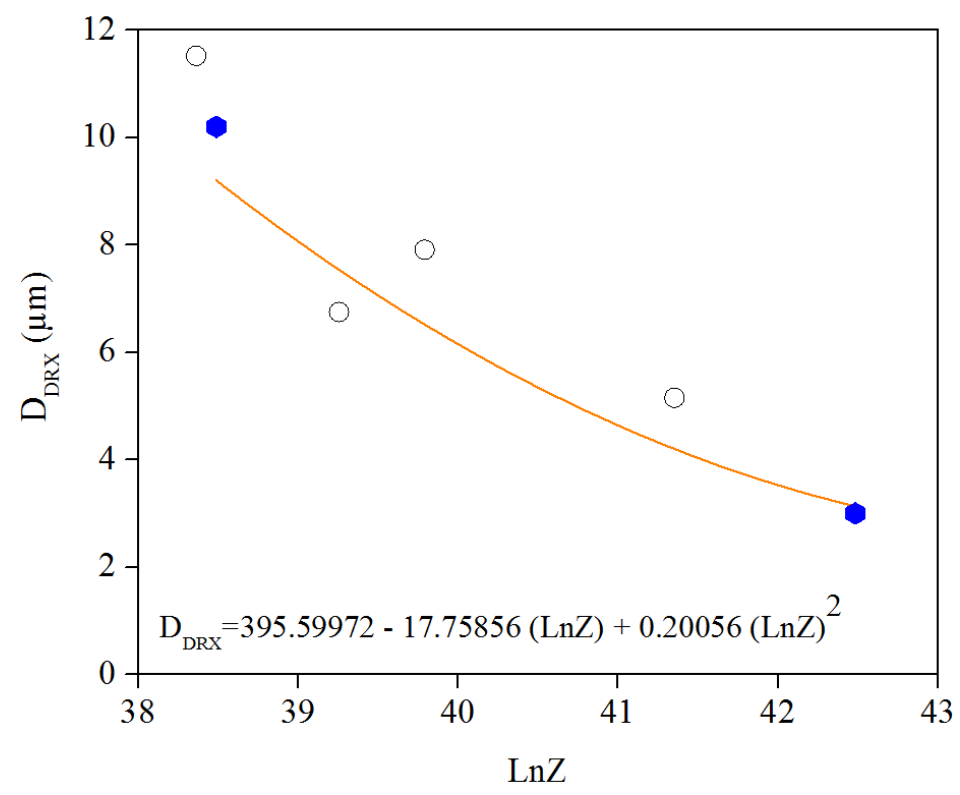

Figure 10: Relationship between recrystallized grain size and Zener-Hollomon parameter. Blue points and empty circles are experimental results for the current SLM-printed IN718 and wrought IN718 superalloys, respectively.

It has been reported that in the $950-1100{ }^{\circ} \mathrm{C}$ deformation range and $0.1 \mathrm{~s}^{-1}$ strain rate, subgrain rotation and twining are the two main softening mechanisms during dynamic recrystallization of wrought IN718 super alloy $[4,16,18,36]$. Since the value of $\mathrm{Z}$ for the SLM-printed IN718 is approximately equal to that of the wrought IN718, it can be assumed that the above two mechanisms are also operating during the hot deformation of the investigated material.

\subsection{Microstructure and phase evolution}

To shed more light on the microstructural evolution during the hot deformation processes, a schematic illustration of the microstructure versus true stress-true strain curves is demonstrated in Figure 11. The original microstructure that contains equiaxed-columnar mixed grains transforms to equiaxed grains due to the heating step prior to the hot-deformation test, and thus the initial stages of both tests show the same microstructural features (Figure 11, point 1). Upon loading, samples show resistance to the applied load by which the equiaxed grains are compressed under low strain levels. Generally speaking, work hardening prevents the occurrence of DRX and DRV softening, and thus the flow stress increases rapidly at this stage (between points 1 and 2). At maximum work hardening (point 2), the microstructure shows elongated grains perpendicular to the loading direction. 


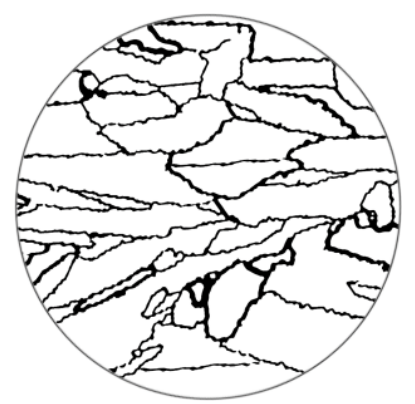

2- Max. work hardening

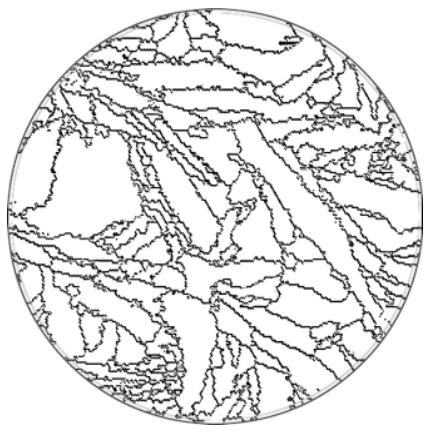

1- Original structure

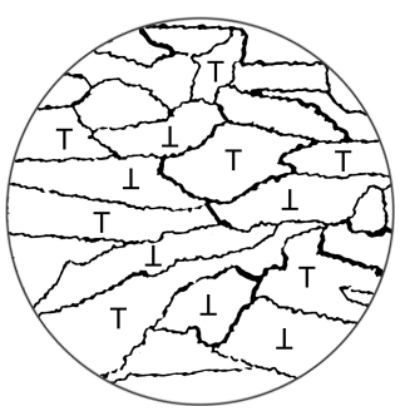

3- Dislocation development
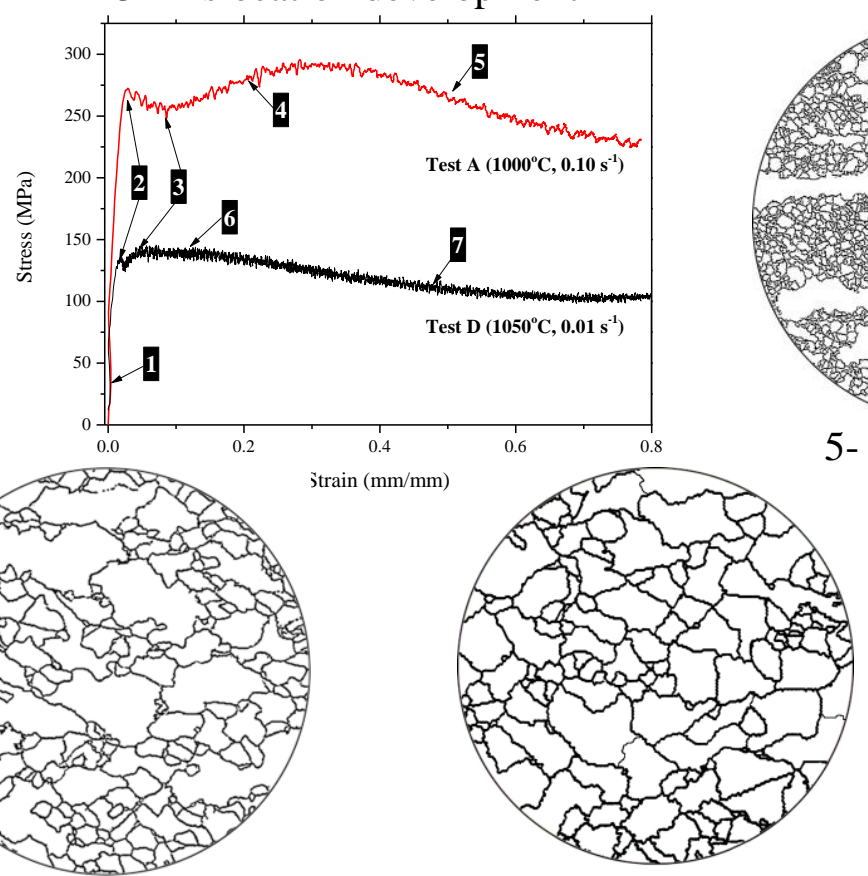

7- DRV structure

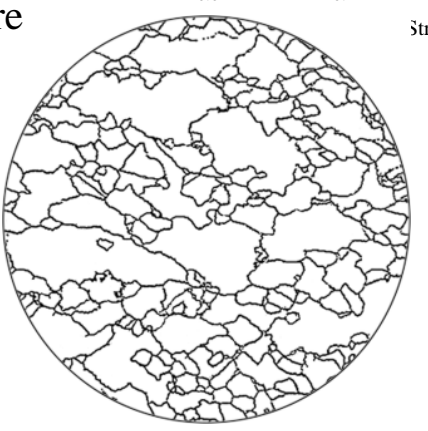

6- Sub-grains formation+DRV

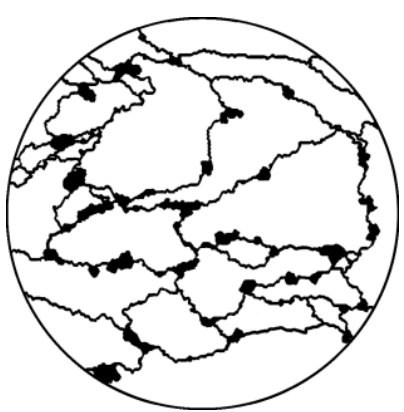

4- First recrystallized

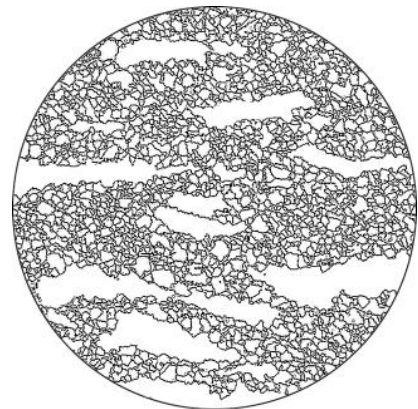

5- DRX structure

Figure 11: Microstructural evolution during Tests $A$ and $D$. The numbers under the microstructure illustrations correspond to those on the stress strain curves.

With continuous loading, the curve drops slightly (point 3) due to the DRV mechanism, as the difference in the dislocation density among grains becomes large. The region between points 3 and 5 is governed by the competition between work hardening, some DRV, and DRX. At point 4, the curve ramps up due to the formation of new recrystallized grains at the grain boundaries. This indicates that the critical driving force for new grain nucleation is attained. These new recrystallized grains are clearly seen after Test A near the short edge, as shown in Figure 7 (a) and (b), but not near the long edge. The situation at point 6 is different from that at point 4 , where the curve starts to drop steadily. At point 6, the process is mostly controlled by DRV. The final stages of true stress-true strain curves, under different temperature and strain rate conditions, show either continuous or steady state drop as a result of the DRX or DRV softening mechanisms. However, any softening is expected to be 
compensated by precipitation hardening. Microstructural and phase analyses are carried out to verify this hypothesis.

The microstructure of the homogenized samples, before Gleeble ${ }^{\circledR}$ testing, consists of $\delta$-phase, MC-type carbides and partially dissolved $\gamma^{\prime \prime}$-phase precipitating within an fcc-Ni $\gamma$-phase matrix [34], as can be seen in Figure 12.
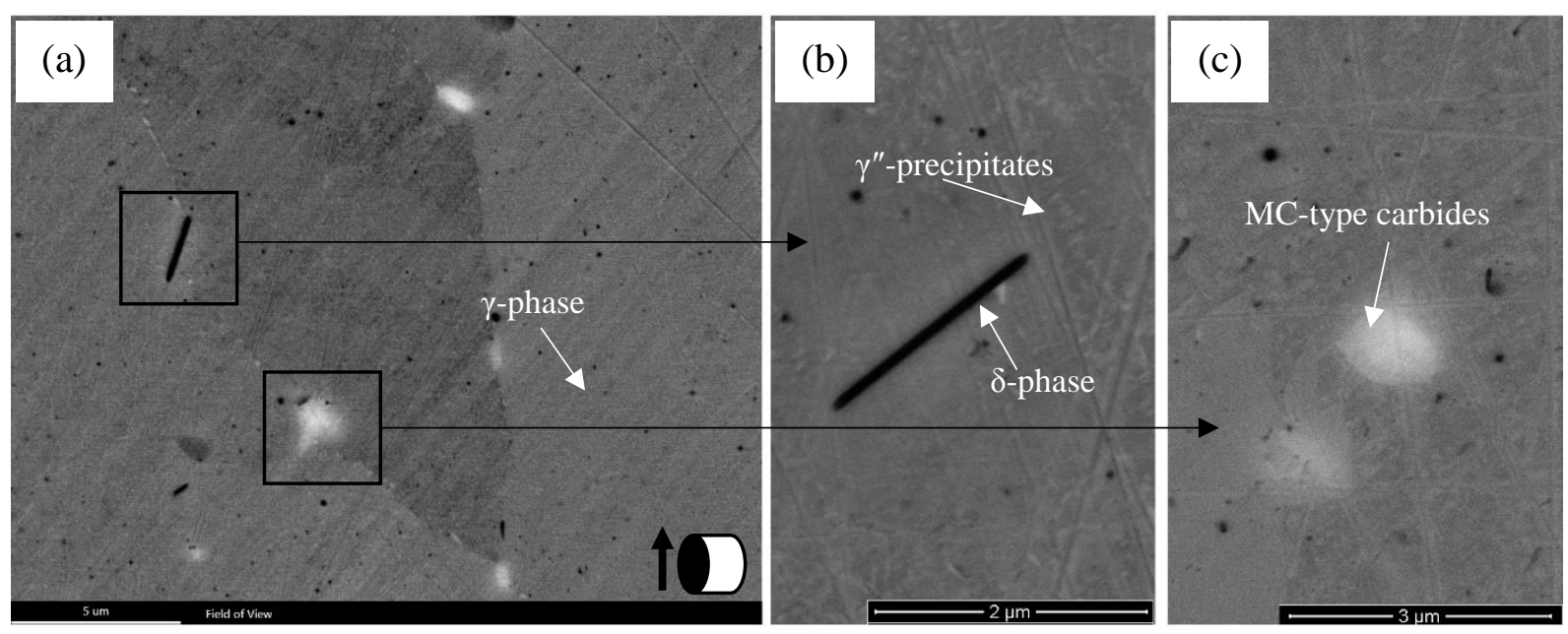

\section{Figure 12: (a) Microstructure of a homogenized sample; (b) and (c) BSE images of $\delta$-phase and MC-type carbides, respectively.}

Figure 13 shows SEM images of Tests A and D at different locations, as indicated by the sketch in the middle. Accordingly, different precipitates were detected at different locations of the vertical axis, and more specifically, were found at the grain boundaries. These precipitates are plate-like phase, $\delta$-phase and MC-type carbides, as shown in Figure 14 (a). The corresponding semiquantitative chemical composition, obtained by EDS spot analysis, for each phase is given in Table 3. Precipitates of $\gamma^{\prime \prime}$-phase were not seen in the tested samples, because they were dissolved in the $\gamma$ matrix upon heating above $900{ }^{\circ} \mathrm{C}$. Both $\delta$-phase and plate-like precipitates were expected to form during the non-equilibrium cooling, as concluded from the precipitation-time-temperature (TTT) diagram of IN718 alloy [37] shown in Figure 15. 

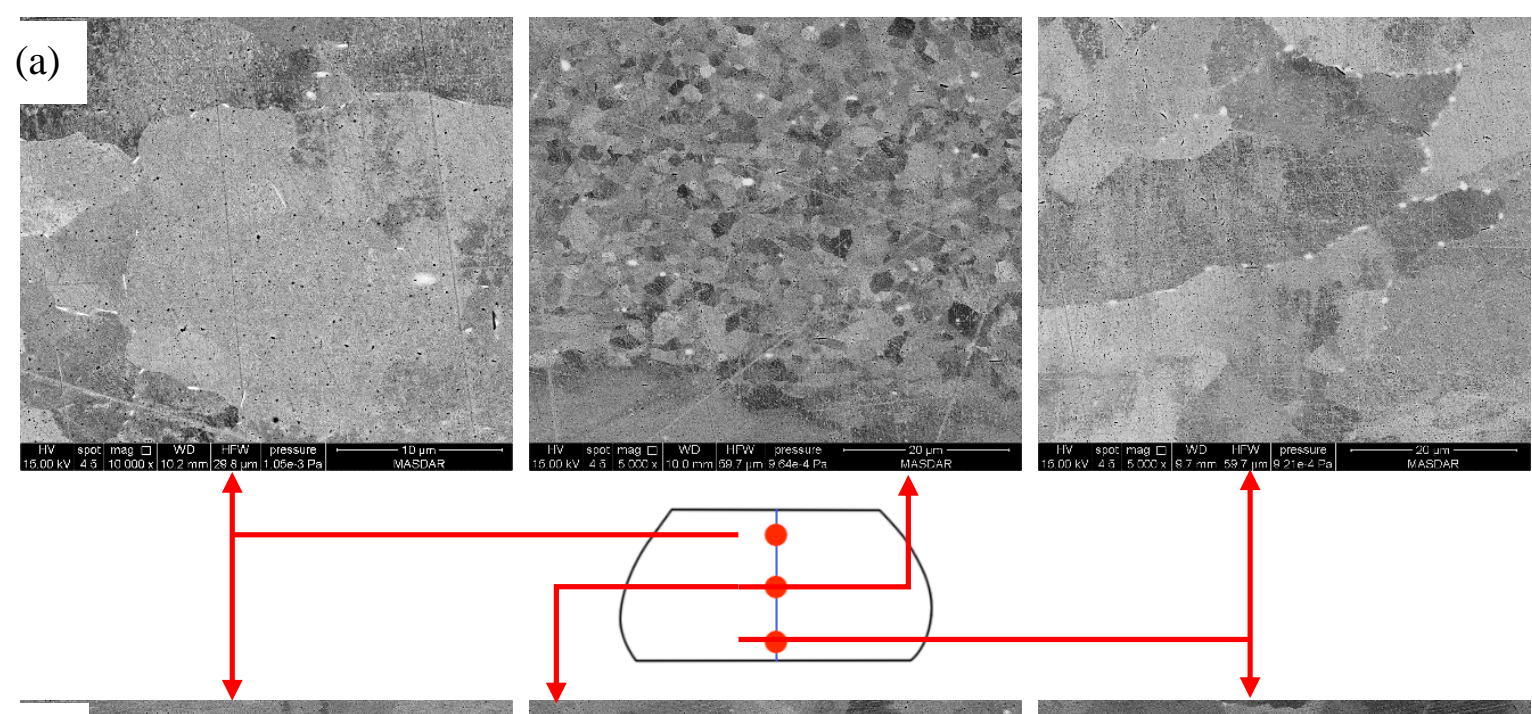

(b)
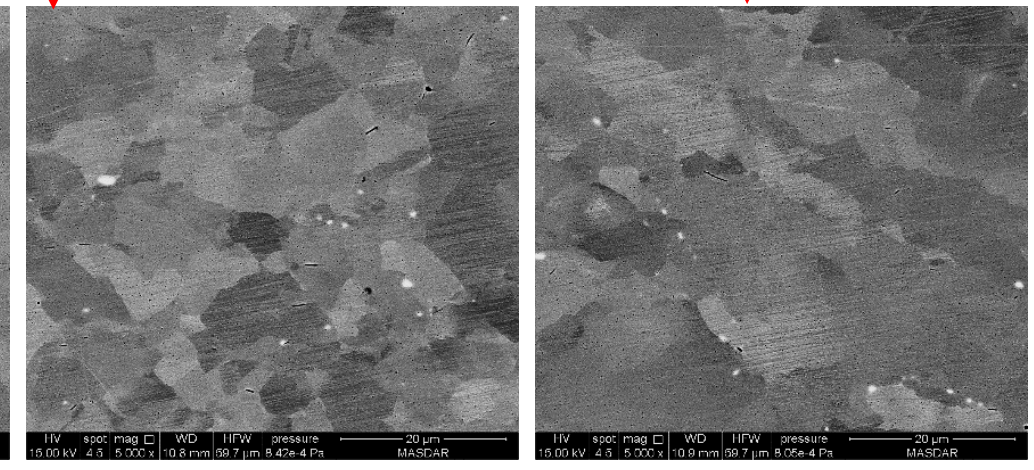

Figure 13: SEM images of (a) Test $A$, and (b) Test $D$ samples with respect to the analysis position on the vertical section.

The plate-like phase, magnified in Figure 14 (b), did not exist in the starting homogenized IN718. EDS analysis is subjected to measurement errors, because the plate-like features are very thin, and thus, the chance of volumetric interaction with the surrounding is very likely. The detection error percentage for each element is reported in Table 3 . There is no doubt that further analysis is required to define this phase. However, the EDS results obtained in this work can be used to predict the composition of unknown phases. According to Muralidharan et al. [38] and Manikandan et al. [39], the Laves phase $\left(\mathrm{Fe}_{2} \mathrm{Nb}\right)$ was detected in the fusion zones of IN718 welds. The stoichiometry of Fe and $\mathrm{Nb}$ in this work was determined using semi-quantitative EDS analysis to be 2.46:1, and thus, by analogy with the reported Laves phase composition [38, 39], it can be said that the plate-like phase is $\left(\mathrm{Fe}_{2} \mathrm{Nb}\right)$ Laves phase. The identification of this phase was not possible using X-ray diffraction because of its small amount. 

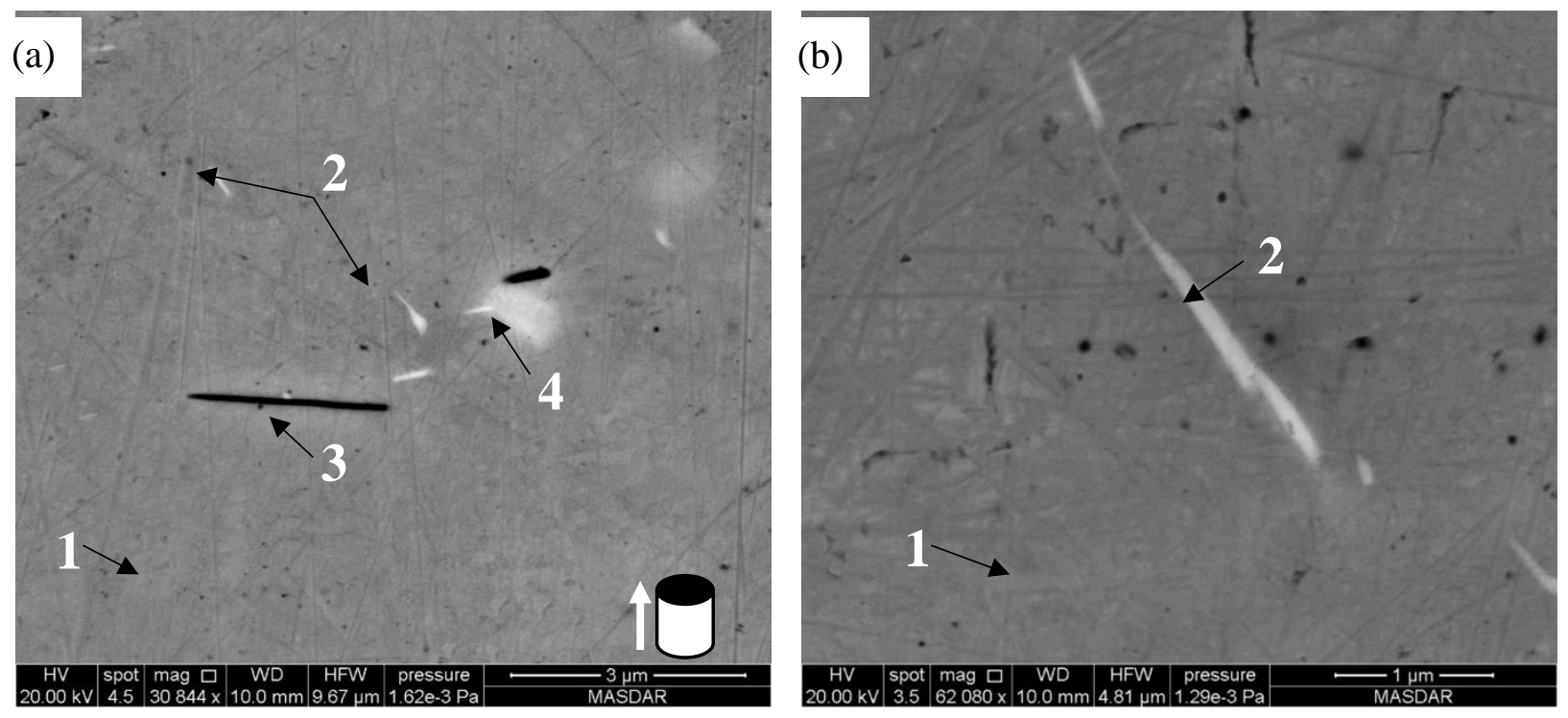

Figure 14: (a) SEM image captures the four phases, $\gamma$-matrix, plate-like phase, $\delta$-phase and MC-type carbides; (b) Magnified image shows the plate-like phase.

Table 3: EDS spot analysis results in at.\% of detected phases (the numbers correspond to those in Figure 14)

\begin{tabular}{|c|l|c|c|c|c|c|c|}
\hline Spot & \multicolumn{1}{|c|}{ Designation } & $\mathrm{Nb}$ & $\mathrm{Mo}$ & $\mathrm{Ti}$ & $\mathrm{Cr}$ & $\mathrm{Fe}$ & $\mathrm{Ni}$ \\
\hline 1 & $\gamma$-matrix & 4.4 & 1.6 & 1.5 & 23.0 & 19.5 & 49.0 \\
\hline 2 & Plate-like & 6.2 & 1.5 & 2.1 & 17.3 & 15.3 & 57.7 \\
\hline 3 & $\delta$-phase & 8.7 & 8.2 & 12.7 & 18.6 & 15.2 & 36.6 \\
\hline 4 & MC-type carbide & 75.4 & - & 24.6 & - & - & - \\
\hline \multicolumn{2}{r|}{ EDS error \% } & 6.7 & 8.8 & 9.5 & 3.2 & 4.0 & 3.0 \\
\hline
\end{tabular}

With reference to the TTT diagram of IN718 welds [37], the Laves phase initially forms at $982{ }^{\circ} \mathrm{C}$ after heating for $1 \mathrm{~h}$ [40]. It should be mentioned that the transformation curves of IN718 welds are shifted towards shorter times, and generally, a slightly higher upper bound transformation temperature as compared to the transformation curves of wrought IN718 alloy reported in [41]. This shift indicates that it is possible to form Laves phase during deformation. The transformation curves in Figure 15 were shifted to shorter times in order to be consistent with the phase formations observed in the samples. Both thermal cycles of Tests A and D pass through a Laves phase formation zone; however, the time duration was not sufficient for it to grow. 


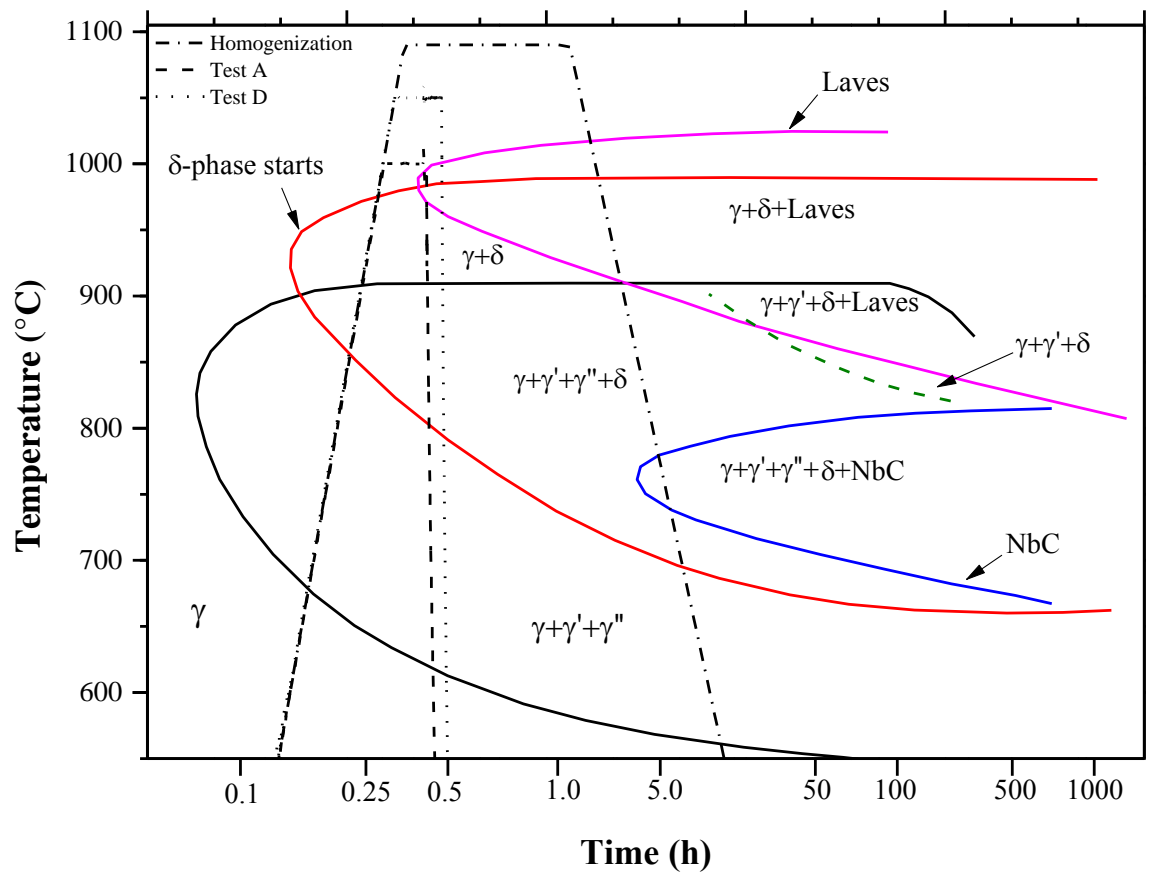

\section{Figure 15: TTT diagram of IN718 welds modified from [37] based on the current Gleeble $^{\circledR}$ results.}

The Laves phase is known to form in Ni-base alloys when the alloying elements, such as $\mathrm{Nb}$, Mo and $\mathrm{Ti}$, exceed their solubility limits in the austenitic matrix. $\mathrm{Nb}$ is considered the major constituent of the Laves phase; nevertheless, the presence of other alloying elements is necessary for Laves to form [42]. In the case of IN718, the Ni-Nb phase diagram [43] does not contain a Laves phase, while in the $\mathrm{Fe}-\mathrm{Nb}$ system the $\mathrm{Fe}_{2} \mathrm{Nb}$ laves phase forms [44]. The amount of $\mathrm{Fe}$ was believed to be sufficient to promote the Laves phase formation with $\mathrm{Nb}$ in IN718 alloy in this study.

The effect of Laves phase on the mechanical properties of IN718 was investigated by Schirra et al. [40]. According to these authors, the presence of Laves phase in cast + HIP samples decreased the alloy's tensile properties at room and elevated temperatures. Furthermore, it promoted the fatigue crack propagation. The amount of Laves phase can be reduced via the homogenization treatment [40, 45], which explains why the Laves phase was not detected in the microstructure of the homogenized samples in this study.

\section{Conclusions}

The mechanical behavior of heat-treated 3D printed IN718 alloy under different temperatures and strain rates were evaluated and discussed in this paper based on crystallographic texture, grain size and microstructure analyses. The true stress-true strain curves revealed that the high temperature mechanical behavior of IN718 alloy is highly dependent on the strain rate. Increasing the strain rate increased the peak stress and shifted the work hardening limits and recrystallization onset towards 
low strain levels. Furthermore, it changed the softening mechanism from DRV to DRX, as could be concluded from the shape of the flow stress curves. Varying the temperature did not change the softening mechanism; it only changed the value of the maximum flow stress. The highest test temperature resulted in the lowest flow stress value. Thus, the lowest strength can be obtained during hot deformation processes by decreasing the strain rate and increasing the deformation temperature. The DRX mechanism was characterized by the development of new grains at the grain boundaries of the original grains, and it was dominant in the $0.1 \mathrm{~s}^{-1}$ strain rate deformation tests. On the contrary, the DRV mechanism was characterized by the development of new grains within the original grains, and was dominant in the $0.01 \mathrm{~s}^{-1}$ strain rate deformation tests. The proposed phenomenological model of the recrystallized grain size vs. Zener-Hollomon parameter can be used to predict the size of recrystallized grains during hot deformation of the SLM-printed IN718 superalloy. Longitudinal and radial thermal gradients were confirmed experimentally and analytically by means of grain size and microstructural analyses. Thermal softening was highly strain rate-dependent, and therefore, the average grain size in the high strain rate tests $\left(0.1 \mathrm{~s}^{-1}\right)$ was smaller than that in the low strain rate tests $\left(0.01 \mathrm{~s}^{-1}\right)$. The formation of secondary phases such as $\delta$-phase, MC-type carbides and Laves phase reduced the overall softening of the alloy.

\section{Acknowledgments}

Ahmad Mostafa, Ignacio Picazo Rubio and Mamoun Medraj acknowledge the financial support received from the Masdar Institute to perform this research. École de technologie supérieure (ÉTS) is acknowledged for providing financial and equipment support in the framework of the Research Chair on Additive Manufacturing (Vladimir Brailovski) and Industrial Research Chair in Forming of High Strength Alloys, CM2P (Davood Shahriari and Mohammad Jahazi), and the National Science and Engineering Research Council (NSERC) in the frame work of Discovery Grant to carry out this research.

\section{References}

[1] F. Chen, J. Liu, H. G. Ou, B. Lu, Z. S. Cui, and H. Long, "Flow characteristics and intrinsic workability of IN718 superalloy," Materials Science and Engineering A-Structural Materials Properties Microstructure and Processing, vol. 642, pp. 279-287, 2015.

[2] Y. C. Lin, D. X. Wen, J. Deng, G. Liu, and J. Chen, "Constitutive models for high-temperature flow behaviors of a Ni-based superalloy," Materials \& Design, vol. 59, pp. 115-123, 2014.

[3] Q. Guo-Zheng, "Characterization for Dynamic Recrystallization Kinetics Based on StressStrain Curves," in Recent Developments in the Study of Recrystallization, P. Wilson, Ed., ed: InTech, 2013. 
[4] L. X. Zhou and T. N. Baker, "Effects of Dynamic and Metadynamic Recrystallization on Microstructures of Wrought in-718 Due to Hot Deformation," Materials Science and Engineering A-Structural Materials Properties Microstructure and Processing, vol. 196, pp. 89-95, 1995.

[5] Y. C. Lin, L. T. Li, Y. C. Xia, and Y. Q. Jiang, "Hot deformation and processing map of a typical Al-Zn-Mg-Cu alloy," Journal of Alloys and Compounds, vol. 550, pp. 438-445, 2013.

[6] A. Nowotnik, "Effect of high temperature deformation on the structure of Ni based superalloy," Journal of Achievements in Materials and Manufacturing Engineering, vol. 27, pp. 115-122, 2008.

[7] A. Nowotnik, P. Pedrak, J. Sieniawski, and M. Goral, "Mechanical properties of hot deformed Inconel 718 and X750," Journal of Achievements in Materials and Manufacturing Engineering, vol. 50, pp. 74-80, 2012.

[8] H. Yuan and W. C. Liu, "Effect of the delta phase on the hot deformation behavior of Inconel 718," Materials Science and Engineering A-Structural Materials Properties Microstructure and Processing, vol. 408, pp. 281-289, 2005.

[9] T. Trosch, J. Strossner, R. Yolkl, and U. Glatzel, "Microstructure and mechanical properties of selective laser melted Inconel 718 compared to forging and casting," Materials Letters, vol. 164, pp. 428-431, 2016.

[10] F. Abe, K. Osakada, M. Shiomi, K. Uematsu, and M. Matsumoto, "The manufacturing of hard tools from metallic powders by selective laser melting," Journal of Materials Processing Technology, vol. 111, pp. 210-213, 2001.

[11] P. L. Blackwell and A. Wisbey, "Laser-aided manufacturing technologies; their application to the near-net shape forming of a high-strength titanium alloy," Journal of Materials Processing Technology, vol. 170, pp. 268-276, 2005.

[12] Alcoa, "The Element of Possibility TM," ed.

[13] Alcoa, " Opens 3D Printing Metal Powder Plant | Additive Manufacturing," ed.

[14] C. I. Garcia, D. E. Camus, E. A. Loria, and A. J. Deardo, "Microstructural Refinement of AsCast Alloy 718 via Thermomechanical Processing," in Superalloys 718, 625 and Various Derivatives, Pittsburgh, PA, USA, 1991, pp. 925-941.

[15] A. Thomas, A. El-Wahabi, J. M. Cabrera, and J. M. Prado, "High temperature deformation of Inconel 718," Journal of Materials Processing Technology, vol. 177, pp. 469-472, 2006.

[16] Y. Wang, W. Z. Shao, L. Zhen, and X. M. Zhang, "Microstructure evolution during dynamic recrystallization of hot deformed superalloy 718," Materials Science and Engineering AStructural Materials Properties Microstructure and Processing, vol. 486, pp. 321-332, 2008.

[17] M. J. Weis, M. C. Mataya, S. W. Thompson, and D. K. Matlock, "The hot deformation behavior of an as-cast alloy 718 ingot," in Int. Symp. Alloy 718 Metall. Appl., Pittsburgh, PA, USA, 1989, pp. 135-154.

[18] L. X. Zhou and T. N. Baker, "Effects of Strain-Rate and Temperature on Deformation-Behavior of in 718 during High-Temperature Deformation," Materials Science and Engineering AStructural Materials Properties Microstructure and Processing, vol. 177, pp. 1-9, 1994.

[19] C. J. Bennett, S. B. Leen, E. J. Williams, P. H. Shipway, and T. H. Hyde, "A critical analysis of plastic flow behaviour in axisymmetric isothermal and Gleeble compression testing," Computational Materials Science, vol. 50, pp. 125-137, 2010.

[20] D. Clark, M. R. Bache, and M. T. Whittaker, "Shaped metal deposition of a nickel alloy for aero engine applications," Journal of Materials Processing Technology, vol. 203, pp. 439-448, 2008.

[21] H. Hany, E. Khamis, Q. Chunlei, M. A. Ali, J. E. A. Nicholas, and M. A. Moataz, "Net-shape manufacturing using hybrid selective laser melting/hot isostatic pressing," Rapid Prototyping Journal, vol. 23, pp. 720-726, 2017. 
[22] E. G.-E. O. Systems, "EOS NickelAlloy IN718 Datasheet," ed: Munich, Germany, 2014.

[23] C. I. Garcia, G. D. Wang, D. E. Camus, E. A. Loria, and A. J. Deardo, "Hot Deformation Behavior of Superalloy-718," Superalloys 718, 625, 706 and Various Derivatives, pp. 293-302, 1994.

[24] F. J. Humphreys and M. Hatherly, Recrystallization and related annealing phenomena, 2 ed.: Elsevier, 2004.

[25] Y. V. R. K. Prasad and N. Ravichandran, "Effect of Stacking-Fault Energy on the Dynamic Recrystallization during Hot-Working of Fcc Metals - a Study Using Processing Maps," Bulletin of Materials Science, vol. 14, pp. 1241-1248, 1991.

[26] A. A. Guimaraes and J. J. Jonas, "Recrystallization and aging effects associated with the high temperature deformation of waspaloy and inconel 718," Metallurgical Transactions A, vol. 12, pp. 1655-1666, 1981.

[27] T. Matsui, "High Temperature Deformation and Dynamic Recrystallization Behavior of Alloy718," Materials Transactions, vol. 54, pp. 512-519, 2013.

[28] H. Monajati, A. K. Taheri, M. Jahazi, and S. Yue, "Deformation characteristics of isothermally forged UDIMET 720 nickel-base superalloy," Metallurgical and Materials Transactions A, vol. 36, pp. 895-905, 2005.

[29] A. Chamanfar, M. Jahazi, J. Gholipour, P. Wanjara, and S. Yue, "Evolution of flow stress and microstructure during isothermal compression of Waspaloy," Materials Science and Engineering A-Structural Materials Properties Microstructure and Processing, vol. 615, pp. 497-510, 2014.

[30] K. Chadha, D. Shahriari, R. Tremblay, P. Bhattacharjee, and M. Jahazi, "Deformation and Recrystallization Behavior of the Cast Structure in Large Size, High Strength Steel Ingots: Experimentation and Modeling," Metallurgical and Materials Transactions A-Physical Metallurgy and Materials Science, vol. 48A, pp. 4297-4313, 2017.

[31] E. Kardoulaki, J. G. Lin, D. Balint, and D. Farrugia, "Investigation of the effects of thermal gradients present in Gleeble high-temperature tensile tests on the strain state for free cutting steel," Journal of Strain Analysis for Engineering Design, vol. 49, pp. 521-532, 2014.

[32] K. Kim, K. H. Oh, and D. N. Lee, "Mechanical behavior of carbon steels during continuous casting," Scripta Materialia, vol. 34, pp. 301-307, 1996.

[33] C. L. Zhang, M. Bellet, M. Bobadilla, H. F. Shen, and B. C. Liu, "Inverse finite element modelling and identification of constitutive parameters of UHS steel based on Gleeble tensile tests at high temperature," Inverse Problems in Science and Engineering, vol. 19, pp. 485-508, 2011.

[34] A. Mostafa, I. P. Rubio, V. Brailovski, M. Jahazi, and M. Medraj, "Structure, Texture and Phases in 3D Printed IN718 Alloy Subjected to Homogenization and HIP Treatments," Metals, vol. 7, 2017.

[35] C. Zener and J. H. Hollomon, "Effect of Strain Rate Upon Plastic Flow of Steel," Journal of Applied Physics, vol. 15, pp. 22-32, 1944.

[36] Y. Wang, W. Z. Shao, L. Zhen, L. Yang, and X. M. Zhang, "Flow behavior and microstructures of superalloy 718 during high temperature deformation," Materials Science and Engineering AStructural Materials Properties Microstructure and Processing, vol. 497, pp. 479-486, 2008.

[37] R. G. Thompson, J. R. Dobbs, and D. E. Mayo, "The Effect of Heat Treatment on Microfissuring in Alloy 718," Welding Research Supplement, vol. 65, pp. 299s-304s, 1986.

[38] B. G. Muralidharan, V. Shankar, and T. P. S. Gill, " Weldability of Inconel 718 - A review," Indira Gandhi Centre for Atomic Research, Tamil Nadu, INDIA1996.

[39] S. G. K. Manikandan, D. Sivakumar, K. Prasad Rao, and M. Kamaraj, "Laves phase in alloy 718 fusion zone- microscopic and calorimetric studies," Materials Characterization, vol. 100, pp. 192-206, 2015. 
[40] J. J. Schirra, R. H. Caless, and R. W. Hatala, "The effect of laves phases on the mechanical properties of wrought and cast+HIP Inconel 718," in Superalloys 718, 625 and Various Derivatives, Pittsburgh, PA, USA, 1991, pp. 375-388.

[41] A. Oradei-Basile and J. F. Radavich, "A current TTT diagram for wrought alloy 718," in Superalloys 718, 625 and Various Derivatives, Pittsburgh, PA, USA, 1991, pp. 325-335.

[42] G. A. Knorovsky, M. J. Cieslak, T. J. Headley, A. D. Romig, and W. F. Hammetter, "Inconel718 - A Solidification Diagram," Metallurgical Transactions A-Physical Metallurgy and Materials Science, vol. 20, pp. 2149-2158, 1989.

[43] H. L. Chen, Y. Du, H. H. Xu, Y. Liu, and J. C. Schuster, "Experimental investigation of the Nb-Ni phase diagram," Journal of Materials Science, vol. 40, pp. 6019-6022, 2005.

[44] T. B. Massalski, H. Okamoto, P. R. Subramanian, and L. Kacprzak, Binary alloy phase diagrams vol. 3. Ohio, USA: ASM International, 1990.

[45] C. Radhakrishna and K. P. Rao, "The formation and control of Laves phase in superalloy 718 welds," Journal of Materials Science, vol. 32, pp. 1977-1984, 1997. 